\title{
Integrated energy simulation of a deep level mine cooling system through a combination of forward and first-principle models applied to system-side parameters
}

\section{Waldo Bornman $^{1 * *}$; Jaco Dirker ${ }^{1 *}$; Deon C. Arndt ${ }^{2}$; Josua P. Meyer ${ }^{1}$}

${ }^{1}$ Department of Mechanical and Aeronautical Engineering, University of Pretoria, Pretoria, Private Bag X20, Hatfield 0028, South Africa.

${ }^{2}$ Enoveer Engineering Innovation, Pretoria, PO Box 60111, Pierre van Ryneveld 0045, South Africa

* Corresponding Author:

Email Address: waldo.bornman@gmail.com

Phone +27(0)823181847

**Alternative Corresponding Author:

Email Address: jaco.dirker@up.ac.za

Phone: $+27(0) 124202465$

\section{Highlights}

- Proposition of an integrated mine cooling system energy modelling method.

- The model is be calibrated with system measured or manufacturer data.

- Major energy consuming devices include chillers, cooling towers, pumps and fans.

- Model parameter identification achieved RMSRE values between 0.0114 and 0.0651 .

- An overall absolute average error between $2.5 \%$ and $3.5 \%$ was obtained. 


\begin{abstract}
Mine cooling systems typically account for around 25\% of the total electrical energy consumption of deep level mines. Numerous energy saving strategies have been implemented; with various levels of success. Most of the previously implemented strategies involved load shifting, energy efficiency and demand reduction. To achieve this, some levels of control are often introduced to control chilled water consumption, water and air mass flow rates as well as scheduling cooling system operation in order to shift the load primarily to offpeak periods.
\end{abstract}

To support and sustain further reduction of energy consumption and optimisation of savings, a simulation model of the integrated cooling system represented by smooth and continuous equations is needed to assist the optimisation computation. This study focused on developing such an integrated mine cooling system simulation model to mimic the thermal hydraulic behaviour along with the energy consumption of the complete mine cooling system. This was achieved by coupling various models representing the major cooling system components such as chillers, cooling towers, pumps and fans together. Although various cooling system energy simulations were considered before, very few quantify the simulation accuracy on a component basis; furthermore, only limited cases were found where the entire system was considered. For these cases not all components were always based on explicit models which would eliminate the requirement for iterative computation which deter optimisation applications.

The simulation model was used to predict the energy consumption of the integrated cooling system of a deep level gold mine in South Africa. The simulation model obtained an average error when compared to the mine's system data of $3.5 \%$ for a selected dataset and $2.5 \%$ for 
another dataset one month later. The successful energy simulation of an integrated mine cooling system would allow for a holistic view on the total power consumption as one parameter or any combination of parameters of the system changes.

\section{Keywords}

Simulation; Cooling system; Modelling; Energy Efficiency

\section{Nomenclature}

\begin{tabular}{|c|c|}
\hline$A$ & area $\left[\mathrm{m}^{2}\right]$ \\
\hline$B A C$ & bulk air cooler \\
\hline$C$ & local loss coefficient \\
\hline$C_{p}$ & specific heat capacity $[\mathrm{J} / \mathrm{kg} \mathrm{K}]$ \\
\hline$C C$ & cooling capacity $[\mathrm{W}]$ \\
\hline$C C T$ & condenser cooling tower \\
\hline$C O P$ & coefficient of performance \\
\hline$D_{h}$ & hydraulic diameter $[\mathrm{m}]$ \\
\hline$f$ & friction factor \\
\hline$h$ & enthalpy $[\mathrm{J} / \mathrm{kg}]$ \\
\hline HVAC & heating ventilation and air conditioning \\
\hline$k$ & flow admittance $\left[\mathrm{m}^{4}\right]$ \\
\hline$L$ & length $[\mathrm{m}]$ \\
\hline$\dot{m}$ & mass flow rate $[\mathrm{kg} / \mathrm{s}]$ \\
\hline MIN & minimum \\
\hline$N$ & dataset length \\
\hline$P$ & pressure $[\mathrm{Pa}]$ \\
\hline$P C T$ & pre-cooling tower \\
\hline$\dot{Q}$ & cooling [W] \\
\hline$R$ & correlation coefficient \\
\hline$R H$ & relative humidity \\
\hline RMSRE & root mean square of relative error \\
\hline
\end{tabular}


SCADA supervisory control and data acquisition system

T temperature $\left[{ }^{\circ} \mathrm{C}\right]$

$V \quad$ velocity $[\mathrm{m} / \mathrm{s}]$

$\dot{W} \quad$ power $[\mathrm{W}]$

\section{Sub- and super-scripts}

\begin{tabular}{|c|c|}
\hline$a$ & air \\
\hline$A M B$ & ambient \\
\hline avg & average \\
\hline$B A C$ & bulk air cooler \\
\hline calc & calculated \\
\hline$C C T$ & condenser cooling tower \\
\hline $\operatorname{cir}$ & circulation \\
\hline cond & condenser \\
\hline$D B$ & dry bulb \\
\hline evap & evaporator \\
\hline$f$ & fan \\
\hline$i$ & inlet \\
\hline$j, k$ & index numbers \\
\hline$m$ & motor \\
\hline $\min$ & minimum \\
\hline mine & mine \\
\hline$o$ & outlet \\
\hline$p$ & pump \\
\hline$P C T$ & pre-cooling tower \\
\hline plant & plant \\
\hline real & measured value \\
\hline ref & refrigeration plant \\
\hline$s$ & saturation \\
\hline $\operatorname{sim}$ & simulated \\
\hline$w$ & water \\
\hline$W B$ & wet bulb \\
\hline
\end{tabular}




\section{Greek letters}

$\begin{array}{ll}\phi & \text { saturated enthalpy/water temperature } \\ \beta & \text { effective heat transfer coefficient }[\mathrm{W} / \mathrm{K}] \\ \rho & \text { density }\left[\mathrm{kg} / \mathrm{m}^{3}\right] \\ \eta & \text { efficiency } \\ \tau & \text { parameter value }\end{array}$

\section{Introduction}

Cooling systems, in particular mine cooling systems, are large energy consumers. Mine cooling systems consume in the region of $25 \%$ of a typical deep level mine's total energy consumption [1, 2]. Many scenarios have been investigated and some measures were implemented to reduce mine energy consumption. This included demand reductions and load shifting initiatives which resulted in reported energy saving of between $8.3 \%$ and $15 \%$ [3-6]. Other methods included varying the rotational speeds of the pumps responsible for supplying water to evaporators, condensers and bulk air coolers (BACs). This resulted in reported energy savings of between $32 \%$ and $33 \%$ for the cooling system [7 - 9].

In order to further reduce cooling system energy consumption, an integrated investigation is needed to quantify the contribution towards the total consumption of each subcomponent within a system. To achieve this, an integrated simulation model of a complete cooling system is required to determine the interdependent influences of the dominant operating parameters within the subcomponent (and any combination of those) on the system's total energy consumption.

Numerous cooling system component modelling approaches can be found in literature $[2,10$ 34]. However, none were found for mine cooling applications which included the modelling 
of an entire system simultaneously. Several investigations were indeed found which focused on building Heating Ventilation and Air Conditioning (HVAC) applications. Because HVAC systems often also rely on chilled water plants, as is the case in mine cooling systems, several similarities exists between building HVAC systems and deep level mine cooling systems in terms of the heat transfer fundamentals and thermodynamics principles at play. For this reason, a brief overview of HVAC related literature is of interest.

Romero et al. [10] used a black box modelling approach to determine the water outlet temperature of a HVAC cooling system when constant condenser conditions were assumed. They stated that the cooling capacity of a refrigeration machine changes, ceteris paribus, as the inlet temperature varies. It was reported that the quality of the model predictions were in the range of $69 \%$ to $76 \%$. Li et al. [14] and Ali et al. [16] used Modelica simulation models for their cooling systems used in commercial buildings. Li et al. [14] only modelled the cooling tower while Ali et al. [16] considered more components of the cooling system. Li et al. [14] used the cooling tower fan speed as the control variable input to the optimisation controller, while the condenser water flow rate was assumed constant. Both these studies suggested significant energy saving potential, although neither explicitly reported on the modelling accuracy. Various studies used the TRNSYS modelling tool as part of simulation based optimisation approaches to model their cooling systems. Fong et al. [29] considered the chiller water inlet temperature set-point and the supply air-temperature set-point as control variables in order to achieve annual energy consumption savings of between $0.15 \%$ and $6.7 \%$ on HVAC systems. Vakiloroaya et al. [31] considered the cooling tower, cooling coil, evaporative cooling system and the air-to-air heat exchanger as part of their HVAC model to achieve modelling accuracies where $24 \%$ of the predicted data deviated by more than $5 \%$ from the actual data. They reported a saving potential of $52 \%$ by replacing the central cooling 
plant with a hybrid evaporative cooling system. Chow et al. [19] included water cooled chillers, constant speed primary chilled water pumps, variable speed secondary chilled water pumps, heat exchangers and straight pipes as part of their model. Another study included refrigerant mass flow; chilled-water temperature and supply air temperature as part of their control variables, while the cooling demand and ambient air dry-bulb temperature were considered uncontrolled variables [21]. Their model achieved similar accuracies to the one presented by Vakiloroaya et al. [31].

Zing et al. [24] considered steady-state chiller models to model the system consisting of a district cooling and heating facility for six residential homes. No report on the integrated simulation accuracy was found, however, correlations having coefficients of determination in the range of between 0.8 and 0.97 was obtained when various climatic zones were modelled. Ding [25] and Afram et al. [26] reviewed various cooling system modelling methods and concluded that simple component models should be considered and be integrated for larger cooling systems in order to achieve acceptable stability, rapidness and accuracy as these parameters are often in conflict when simulation models are attempted. Afram et al. [26] and Lee and $\mathrm{Lu} \mathrm{[34]} \mathrm{categorised} \mathrm{cooling} \mathrm{system} \mathrm{modelling} \mathrm{into} \mathrm{three} \mathrm{different} \mathrm{categories} \mathrm{namely}$ a data driven (black box) approach; a physics based (white box) approach and a grey box approach which is a combination of the first two. Afram et al. [26] suggested that there exists a trade-off between the white box and black box approach in that the white box is more generic while the accuracy is reduced and vice versa for the black box approach. Lee and Lu [34] advises that although black-box models are easier to set up, they cannot be used to extrapolate performance beyond the data range for which they were developed. In their thermal modelling approach, Mofet and Zmeureanu [32] considered the degradation of the accuracy thermal models over time. After they have trained their model, they achieved Root- 
Mean-Squared-Error (RMSE) values less than $7 \%$ for the remainder of the same summer season and less than $8 \%$ for the following summer season. Their study suggested that the primary reason for the deterioration of the modelling accuracy when applying it to time spans further away from when the training data was collected is due to the cooling demand and ambient conditions being significantly different from those during the training period. $\mathrm{Du}$ Plessis et al. [2] modelled the effects of variable water flow on mine cooling systems by examining the impact of evaporator, condenser and Bulk Air Cooler (BAC) water flow rate adjustments. Although no quantification of the various system component models' accuracies were given, an integrated simulation accuracy with an average error of $4.1 \%$ was achieved.

From the studies considered above, no component-based integrated energy simulation model which is based on system-side parameters has been constructed and quantified for a deep level mine cooling system. The successful development of such a model would allow a holistic analysis of variations in any sub component's operational parameters and its effect on the integrated system's energy consumption. This would be of great value because the effects that alterations to one component would have on all the others are often not considered during operation and maintenance of these systems. It would furthermore facilitate the possibility to couple such a model to an optimisation platform granting the opportunity to determine overall energy optimal operation of the integrated system for variations in demand and other uncontrollable external parameters.

In order to obtain an integrated cooling system energy model based on the requirements specified suitable thermal hydraulic component energy models for the major system energy consuming components would be required. This will allow the simulation of the integrated 
system by coupling the component models together to form the complete system where the outlet of one component will become the inlet to the next.

\subsection{Purpose of the study}

The objective of this study was to propose an integrated energy modelling method for a deep level mine cooling system, whereby the effect of altering any control or input variable of any component, or any combination thereof, would simulate the influence on the entire system. Modelling the integrated system will allow overall system optimisation through the coupling with a suitable optimisation algorithm. In order to achieve this, a modelling method consisting of smooth and continuous functions without step changes was required for the entire system. It must be noted that optimisation (in specific) falls outside the scope of this study. Rather, focus is placed on developing a relevant model for integrated system simulation.

The rest of this paper is structured in four parts. Firstly; the case study integrated cooling system that is used in this paper is presented; secondly suitable component (sub-system) models for the various components of the cooling system are described; thirdly operational thermal data points are used to calibrate and validate the models; and finally, the sub-system models are coupled together to form the integrated system model. This is used to simulate the total system energy consumption and to compare it to the measured total system power logged on the mine's data system. 


\section{Mine Cooling System}

Figure 1 gives a schematic overview of the integrated mine cooling system used as the case study in this paper. It reflects the cooling system employed at a deep level gold mine located on the moderate cold eastern plateau interior of South Africa at an altitude of $1336 \mathrm{~m}$. The name of the mine is treated anonymously due to their confidentiality requirements. The underground mine is supplied with cooled ventilation air, as well as chilled water.

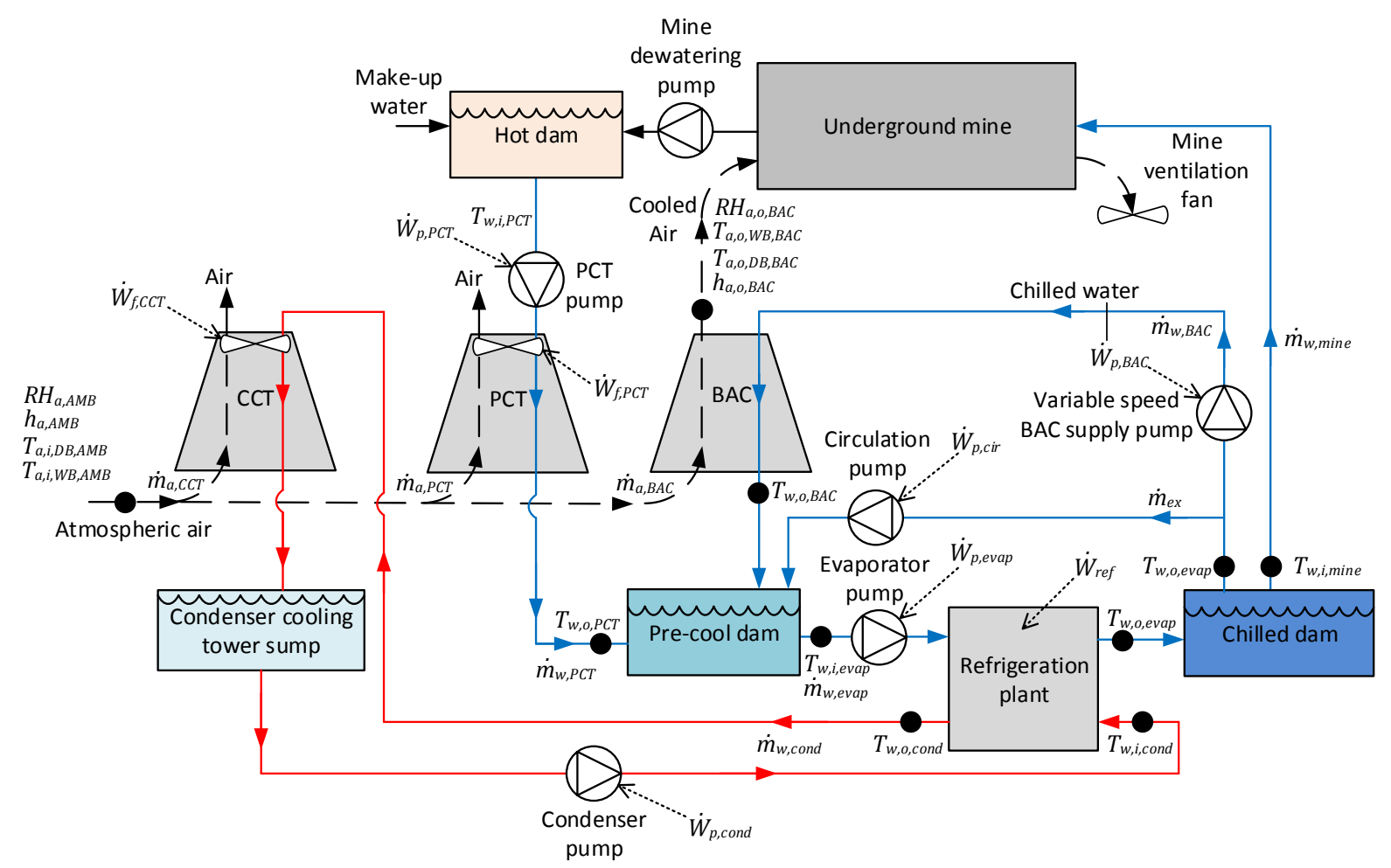

Figure 1 Representation of the integrated mine cooling system considered in this paper

The cooling system consists of a combination of a refrigeration plant with storage dams, cooling towers, and bulk air coolers; and will be discussed in detail in the sections that follow. Firstly, an overview of the refrigeration plant is given. Next, the water circulation system (blue flow lines in Figure 1) that passes through the evaporators of the refrigeration plant is discussed. Then, a discussion is given of the water circulation systems that pass through the condensers of the refrigeration plant (red flow lines in Figure 1). Lastly, details 
of the measuring and data capturing system are given. The typical design operational setpoints and control of all relevant components are described in later sections of this paper.

\subsection{Refrigeration plant}

Fig. 2 schematically shows the configuration of the refrigeration plant containing six parallel chiller machines. The evaporators and condensers are shell and tube heat exchangers with the refrigerant flowing external to the tubes while water flows inside the tubes. The water flows through the evaporators are used to service the cooling needs of the mine, while the water flows through the condenser are used to transport energy to cooling towers for expulsion into the atmosphere. The chillers are operated through centrifugal compressors which incorporate inlet guide vane control for partial cooling operation. The total power input to the refrigeration plant via the compressor motors is denoted by $\dot{W}_{\text {ref }}$. More details of the water flow circuits are given in the sections that follow.

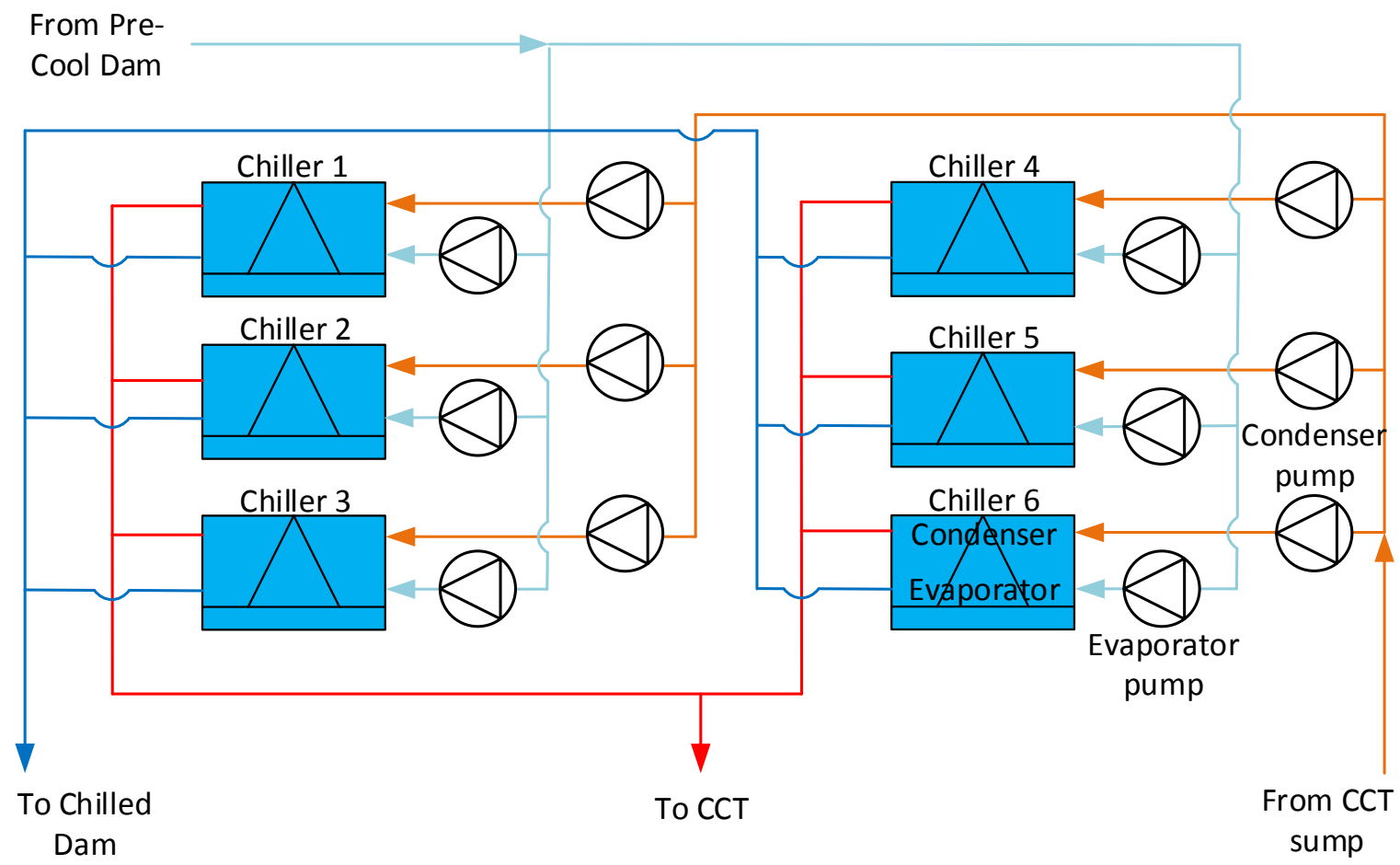

Figure 2 Chiller machine arrangement inside refrigeration plant 


\subsection{Water circuit connected to the evaporators}

Please refer to the blue flow circuits in Figure 1 for the water loop through the mine and the water loop through the Bulk Air Coolers (BACs).

Warm water is drawn from the mine via the dewatering pumps and is stored in a hot water storage dam. This dam also receives make-up water in order to maintain a water balance. From the hot dam, the water is sent through the forced draft open Pre-Cooling Towers (PCTs). The PCT arrangement consists of two towers connected in parallel operated both at the same load with fixed air flow rates but with the same variable water flow rates controlled via variable speed pumps at a combined mass flow rate of $\dot{m}_{w, P C T}$. The water supply is provided through a common supply pipe configuration. The PCTs have water inlet and outlet temperatures of $T_{w, i, P C T}$ and $T_{w, o, P C T}$ respectively. The pumps and fans have total power consumptions of $\dot{W}_{p, P C T}$ and $\dot{W}_{f, P C T}$ respectively.

After the PCTs, the pre-cooled water is stored in a pre-cool storage dam before it is pumped through the evaporators of the refrigeration plant by variable speed pumps at a combined flow rate of $\dot{m}_{w, \text { evap }}$ such that the combined evaporator water pump power consumption is $\dot{W}_{p, \text { evap }}$. For simplicity, the six evaporator pumps are represented in Figure 1 as a single pump. The evaporators are used to cool the water from an average inlet temperature of $T_{w, i, e v a p}$ to an average outlet temperature of $T_{w, o, e v a p}$.

Following the refrigeration plant, the chilled water is stored in a chilled water storage dam. From here, the chilled water is dispatched in relevant proportions back to the mine, and/or to the BACs for cooling the mine ventilation air, and/or recirculated back to the pre-cool dam for additional pre-cooling if required. 
Chilled water enters the mine via gravity feed at a mass flow rate and a temperature of $\dot{m}_{w, \text { mine }}$ and $T_{w, i, m i n e}=T_{w, \text { o,evap }}$. Simultaneously, chilled water enters the forced draft direct contact BACs at a temperature of $T_{w, i, B A C}=T_{w, o, \text { evap }}$ at a flow rate of $\dot{m}_{w, B A C}$ which is controlled with variable speed pumps with a combined power consumption of $\dot{W}_{p, B A C}$. The BAC configuration consists of three towers operated in parallel with all three operating at the same load. The air flow rate is varied in accordance with the mine ventilation requirements by controlling the ventilation fan flow. The water exiting the BACs at a temperature of $T_{w, o, B A C}$ passes into the pre-cool storage dam and is mixed with the water from the PCTs.

The remaining (excess) water (not dispatched to the mine or the BACs) is circulated directly back to the pre-cool dam via a circulation pump at a rate of $\dot{m}_{w, e x}$. The power consumption of this pump is $\dot{W}_{p, c i r}$.

\subsection{Water circuit connected to the condensers}

Please refer to the red flow circuits in Figure 1. As mentioned, the condensers of the refrigeration plant are water-cooled. Each condenser is serviced by a separate water loop consisting of a forced draft Condenser Cooling Tower (CCT), a common CCT sump and a variable speed water pump. Therefore, the CCT arrangement consists of six towers, one for each chiller machine dumping the cooled condenser water into a common sump from where the condenser water is pumped individually to each chiller in operation. For simplicity, these six flow loops are represented in Figure 1 as a single flow loop. Each tower operates independently based on its chiller machine status and load, therefore each CCT has a unique inlet temperature and flow rate which is determined by the flow controlled by the variable speed condenser pumps. The condenser water inlet temperature is typically the same for all chiller machines as it is supplied from the common CCT sump. The combined water mass 
flow rate is $\dot{m}_{w, \text { cond }}$, the combined pump power consumption rate is $\dot{W}_{p, c o n d}$, and the combined cooling tower fan power consumption rate is $\dot{W}_{f, C C T}$. The average condenser water inlet and outlet temperatures are $T_{w, i, c o n d}$ and $T_{w, o, c o n d}$ respectively.

\subsection{Measuring and data capturing system}

Several operating data values were logged on the mine's Supervisory Control and Data Acquisition (SCADA) system during the operation of the cooling system, typically included in the system flow network as indicated in Figure 1. These included: the compressor power input $\left(\dot{W}_{\text {ref }}\right)$ which is calculated on the SCADA system via the current drawn by each compressor as measured at the motor control centre of each chiller machine; the PCT, BAC, condenser, evaporator, circulation and mine underground water flow rates $\left(\dot{m}_{w, P C T}, \dot{m}_{w, B A C}\right.$, $\left.\dot{m}_{w, \text { cond }}, \dot{m}_{w, \text { evap }}, \dot{m}_{w, e x}, \dot{m}_{w, \text { mine }}\right)$ which are measured by means of water flow meters connected in series with each components flow pipes; the PCT, condenser and evaporator water inlet- and outlet-temperatures $\left(T_{w, i, P C T}, T_{w, o, P C T}, T_{w, i, c o n d}, T_{w, o, c o n d}, T_{w, i, e v a p}\right.$, $\left.T_{w, o, e v a p}\right)$ measured before and after the various components via thermometers typically installed in welded thermo-couple sockets; the PCT and CCT fan power as well as the PCT, BAC, condenser, evaporator and circulation pump power $\left(\dot{W}_{f, P C T}, \dot{W}_{f, C C T}, \dot{W}_{p, P C T}, \dot{W}_{p, B A C}\right.$, $\dot{W}_{p, \text { cond }}, \dot{W}_{p, \text { evap }}$ and $\left.\dot{W}_{p, \text { cir }}\right)$ which are included in the total plant power. The total combined cooling system power consumption $\dot{W}_{\text {plant }}$ is also recorded on the SCADA system as measured from the main electrical feeder to the plant.

A weather station is used to measure the ambient weather conditions. It measures the ambient dry-bulb temperature and relative humidity $\left(T_{a, D B, A M B}\right.$ and $\left.R H_{a, A M B}\right)$ respectively. The ambient enthalpy $\left(h_{a, A M B}\right)$ is calculated and fed to the SCADA system along with the 
other parameters. The same weather station device is used downstream of the BACs to measure the air outlet conditions $\left(T_{a, o, D B, B A C}, R H_{a, o, B A C}\right.$ and $\left.h_{a, o, B A C}\right)$. During normal operation of the mine, data is continuously logged by the mine's SCADA system in 3 minute intervals; resulting in 480 data points for each 24-hour day. The accuracy of the measuring instrumentation used on the mine cooling system is summarised in Table 1 [35 - 37].

Table 1 Measuring instrumentation

\begin{tabular}{|l|l|l|l|}
\hline Parameter & Instrument & Unit & Accuracy \\
\hline Water Temperature & Wika Model TC40 Type T thermocouple [37] & ${ }^{\circ} \mathrm{C}$ & $\pm 0.5^{\circ} \mathrm{C}$ \\
\hline Water Flow rate & Krohne UFM 3030 in-line ultrasonic flowmeter [36] & $1 / \mathrm{s}$ & $\pm 0.5 \%$ \\
\hline Air Temperature & Testo 6682 with 6616 probe [35] & ${ }^{\circ} \mathrm{C}$ & $\pm 0.15{ }^{\circ} \mathrm{C}$ \\
\hline Air Relative Humidity & Testo 6682 with 6616 probe [35] & $\%$ & $\pm 1 \%$ \\
\hline
\end{tabular}

\section{Component Models}

In order to model the integrated mine cooling system; sub-models are needed to relate the relevant performance measures of each sub-component to their operating conditions. To achieve this, components were categorised according to their dominance on the total energy consumption of the cooling systems.

Dominant components were the chiller machines, the cooling towers and air coolers (PCTs, BACs and CCTs), the water pumps (evaporator, condenser, PCT supply, BAC supply and circulation) and the forced draft air fans (PCT, BAC, CCT). The mine dewatering pumps are not considered as the current study focuses on the refrigeration plant's energy consumption only. Less dominant components were the water storage dams, pipes and valves. For the 
purpose of this study, the dams and cooling tower sumps as well as all pipes and pumps are assumed to be adiabatic and the make-up water fraction is regarded as insignificant; therefore the time-averaged PCT water flow is assumed to be equal to the flow of the water sent underground, $\dot{m}_{w, P C T}=\dot{m}_{w, \text { mine }}$.

In the sections that follow, the modelling methods used to simulate the energy consumption of the dominant components are described based on their thermal behaviour. A description and summary of each component's design operational parameters are also provided at the beginning of each section.

\subsection{Refrigeration plant}

As mentioned, there were six water cooled chillers in the refrigeration plant; each operated as a vapour compression cycle using R134a. The combined rated cooling capacity was $39000 \mathrm{~kW}$ at a combined design power requirement of $7092 \mathrm{~kW}$ at the compressors. Therefore, the design condition coefficient of performance (COP) was approximately 5.5. The chiller condenser's design operating water inlet and outlet temperatures were $27^{\circ} \mathrm{C}$ and $32{ }^{\circ} \mathrm{C}$ respectively at a total mass flow rate, for all condensers combined, of $2700 \mathrm{~kg} / \mathrm{s}$. The evaporators had a combined design mass flow rate of $1500 \mathrm{~kg} / \mathrm{s}$ at water inlet and outlet temperatures of $9{ }^{\circ} \mathrm{C}$ and $3{ }^{\circ} \mathrm{C}$ respectively. Since the overall impact of the chiller units are of interest in this paper, and the detailed modelling of the internal sub-components fall beyond the scope of this work, a full description of the vapour compression cycle is omitted. Therefore, the internal component parameters are not considered in detail as the intention is not to alter or influence any of these parameters or components but rather to operate the system within the bounds for which the system was designed and generally operated in. 
Various approaches for the modelling of water-cooled chiller machines have been presented in literature as stated earlier. For the purposes of this integrated simulation study where the goal is to use an explicit grey-box modelling approach, the efficiency and energy consumption of the refrigeration plant was to be predicted for any set of inlet conditions ( $T_{w, i, \text { evap }}$ and $\left.T_{w, i, c o n d}\right)$, operating mass flow rates $\left(\dot{m}_{w, \text { evap }}\right.$ and $\left.\dot{m}_{w, \text { cond }}\right)$ and any known desired outlet conditions as the temperature set-points $\left(T_{w, o, \text { evap }}\right.$ and/or $\left.T_{w, o, c o n d}\right)$.

Some methods exist with which the cooling capacity (CC) of a cooling system can be related to its operating temperatures and other parameters using large numbers of coefficients [38]. In the approach considered for the current study, the cooling capacity is considered to be a function of the average evaporator and condenser temperatures [1]. The cooling capacity ultimately represents the maximum amount of cooling that the machine can perform at the given set of evaporator and condenser temperatures and would be a constraint for optimisation applications.

The cooling capacity of the refrigeration plant is expressed empirically with the form given in Eq. (1) [1] in terms of the average evaporator and condenser temperatures, $T_{w, \text { avg,evap }}$ and $T_{w, \text { avg,cond }}$ respectively. The average temperatures refer to the average between the relevant inlet and outlet water temperatures. This simplistic approach, based only on a linear relation between the cooling capacity and the evaporator and condenser water temperatures, was compared to another empirical approach given in [38] where non-linear relationships are used which requires nine coefficients instead of three. It was found that there was only a $0.86 \%$ variation in the prediction of the cooling capacity. Thus, the more simplistic approach was adopted. 
$C C=c_{1} T_{w, \text { avg,evap }}+c_{2} T_{w, \text { avg,cond }}+c_{3}$

Coefficients $c_{1}, c_{2}$ and $c_{3}$ are system specific constants which are determined by performing a least squares method analysis, represented by Eq. (2) [39], using a system dataset of size $N$ obtained either from the manufacturer or from site measurements.

$\left(\left[c_{1}, c_{2}, c_{3}\right]^{T}\right)_{\min }=\operatorname{MIN} \sum_{j=1}^{N}\left(C C_{c a l c, j}-C C_{\text {real }, j}\right)^{2}$

In order to determine parameters $c_{1}, c_{2}$ and $c_{3}$; only system operational points at full-load should be considered in order to capture only the effect that the average evaporator and condenser temperatures would have on the chiller cooling capacity. It is therefore necessary to isolate non partial-load data for this equation's parameter determination.

The electrical power, $\dot{W}_{\text {ref }}$, consumed by the chillers inside the refrigeration plant, can be expressed with Eq. (3).

$\dot{W}_{\text {ref }}=\sum_{j=1}^{6} \frac{\dot{Q}_{w, e v a p, j}}{C O P_{j}}$

Here, $\dot{Q}_{w, e v a p, j}$ is the cooling heat transfer rate supplied to the water flowing through the respective evaporators, expressed by Eq. (4). The Coefficient of Performance (COP) of the refrigeration plant can subsequently be determined empirically by Eq. (5) [34]. 
$\dot{Q}_{w, \text { evap }}=\dot{m}_{w} C_{p}\left(T_{w, i, e v a p}-T_{w, o, e v a p}\right)$

Where $\dot{m}_{w}$ is the mass flow rate of the water through the evaporators of the refrigeration plant while $T_{w, i, e v a p}$ and $T_{w, o, e v a p}$ are the water inlet and outlet temperatures of the evaporators respectively.

The coefficient of performance can be expressed as a function of the water temperatures in the condenser and evaporator as well as the entropy generation occurring in the cooling plant due to friction in the compressor and flow lines, and thermal resistance in the condenser and evaporator. Since the frictional components (to a lesser extent) as well as the thermal resistance (dominated by the single phase convection heat transfer coefficients on the water side) are dependent on the mass flow rates of the water in the condensers and evaporators. The COP can be expressed as a function of the temperature of water in the condensers, the water temperature in the evaporators, and the water mass flow rates. This is acceptable if the vapour compression cycles are well-controlled by their expansion devices and if the phasechange heat transfer mechanisms in the condensers and evaporators are not significantly influenced by the possible variation in the refrigerant mass flow rate (especially when the flow is throttled) and the condensing and evaporating wall temperatures. For instance, Lee and $\mathrm{Lu}$ [34] proposed an empirical model as shown in Eq. (5) [34] and is based on nine system specific coefficients that can be determined from manufacturer data or site measurements. 


$$
\begin{aligned}
\text { COP }=\sigma_{0}+ & \sigma_{1} \dot{Q}_{w, \text { evap }}+\sigma_{2} T_{w, i, \text { evap }}+\sigma_{3} T_{w, i, \text { cond }}+\sigma_{4} \dot{Q}_{w, \text { evap }}{ }^{2}+\sigma_{5} T_{w, i, e v a p}{ }^{2} \\
& +\sigma_{6} T_{w, i, \text { cond }}{ }^{2}+\sigma_{7} T_{w, i, \text { evap }} \dot{Q}_{w, \text { evap }}+\sigma_{8} T_{w, i, \text { cond }} \dot{Q}_{w, \text { evap }} \\
& +\sigma_{9} T_{w, i, \text { cond }} T_{w, i, \text { evap }}
\end{aligned}
$$

Since the water mass flow rates directly impact the heat transfer rates, the presence of the heat transfer rates in Eq. (5) indirectly represents the impact of the mass flow rate and subsequently includes the effect of part load operation as a result. Coefficients $\sigma_{0}$ to $\sigma_{9}$ are system specific constants which can be obtained similar to $c_{1}, c_{2}$ and $c_{3}$ by using Eq. (6) [39]. $\dot{Q}_{w, \text { evap }}$ and $T_{w, i, \text { evap }}$ are defined in Eq. (3) and (4) respectively while $T_{w, i, c o n d}$ represents the condenser water inlet temperature.

$$
\left(\left[\sigma_{1}, \ldots, \sigma_{9}\right]^{T}\right)_{\min }=\operatorname{MIN} \sum_{j=1}^{N}\left(C O P_{c a l c, j}-C O P_{\text {real }, j}\right)^{2}
$$

\subsection{Cooling Towers and Air Coolers}

The PCTs, BACs and CCTs are grouped together because they share the same fundamental modelling approach for heat and mass transfer between a wetted surface and an air stream. Some of their more important design operational parameters are summarised in Table 2 and are briefly discussed in the section that follows.

From Figure 1 it can be seen that the PCTs, BACs and CCTs all draw in atmospheric air which (for the mine at design conditions) is at an ambient air wet bulb temperature of $18{ }^{\circ} \mathrm{C}$ and a specific enthalpy of $50 \mathrm{~kJ} / \mathrm{kg}$. In reality, these values vary greatly and are discussed later in this paper. From Table 2 it can be seen that under design conditions, the PCTs and 
CCTs receive relatively warm water (between $30^{\circ} \mathrm{C}$ and $32^{\circ} \mathrm{C}$ ) which is cooled (through evaporation) by between $5^{\circ} \mathrm{C}$ and $6^{\circ} \mathrm{C}$. On the other hand, the BACs receive relatively cold water (approximately $3^{\circ} \mathrm{C}$ ) which (through sensible and latent heat transfer) enables the cooling of the air flowing into the mine. In terms of the water and air mass flow rates, the CCTs have the highest design condition rating while the PCTs have the lowest design condition rating. The $\mathrm{BAC}$ air flow rate is varied in accordance with the mine ventilation requirements by controlling the ventilation fan flow. The water flow rate is controlled by the ambient weather conditions which linearly reduces the flow through the BAC as the ambient enthalpy reduces.

The CCT circuit rejects heat at a constant air flow rate equal to the design conditions while the water flow rate is controlled by varying the flow through the condenser in order to maintain a $5{ }^{\circ} \mathrm{C}$ temperature differential across the condenser.

Table 2: PCT, BAC and CCT design operational parameters

\begin{tabular}{|l|c|c|c|c|}
\hline \multicolumn{1}{|c|}{ Parameter } & Unit & PCT & BAC & CCT \\
\hline Water mass flow rate & $\mathrm{kg} / \mathrm{s}$ & 360 (maximum) & 750 (maximum) & 2700 (maximum) \\
\hline Water inlet temperature & ${ }^{\circ} \mathrm{C}$ & 30 & 3 & 32 \\
\hline Water outlet temperature & ${ }^{\circ} \mathrm{C}$ & 24 & 9 & 27 \\
\hline Air mass flow rate & $\mathrm{kg} / \mathrm{s}$ & 720 (fixed) & 1250 (maximum) & 1350 (fixed) \\
\hline $\begin{array}{l}\text { Air inlet wet bulb } \\
\text { temperature }\end{array}$ & ${ }^{\circ} \mathrm{C}$ & $18^{\circ} \mathrm{C}$ & $18^{\circ} \mathrm{C}$ & $18^{\circ} \mathrm{C}$ \\
\hline Air inlet specific enthalpy & $\mathrm{kJ} / \mathrm{kg}$ & $50 \mathrm{~kJ} / \mathrm{kg}$ & $50 \mathrm{~kJ} / \mathrm{kg}$ & $50 \mathrm{~kJ} / \mathrm{kg}$ \\
\hline $\begin{array}{l}\text { Air outlet wet bulb } \\
\text { temperature }\end{array}$ & ${ }^{\circ} \mathrm{C}$ & $\mathrm{N} / \mathrm{A}$ & $7{ }^{\circ} \mathrm{C}$ & $\mathrm{N} / \mathrm{A}$ \\
\hline \begin{tabular}{l} 
Air outlet specific enthalpy \\
\hline
\end{tabular} & $\mathrm{kJ} / \mathrm{kg}$ & $\mathrm{N} / \mathrm{A}$ & $27 \mathrm{~kJ} / \mathrm{kg}$ & $\mathrm{N} / \mathrm{A}$ \\
\hline
\end{tabular}

To model the cooling towers with the objective of integrated optimisation, an explicit model is required, which would allow the prediction of the outlet conditions from any set of inlet 
conditions without the requirement for iterative computation. A suitable method for this is by using the approach proposed by Bornman et al. [39] whereby the performance of direct contact cooling towers can be determined by means of a combined forward and first-principle model which is based on underlying energy balance and heat transfer principles. This model is bound by the following assumptions: (1) water loss through evaporation is not significant; (2) the heat transfer surface area remains constant; and (3) the saturation enthalpy is approximately linear in respect to the wet-bulb temperature.

The cooling tower model input parameters include the air inlet specific enthalpy, $h_{a, i}$, the water inlet temperature, $T_{w, i}$, as well as air- and water- mass flow rates $\left(\dot{m}_{a}\right.$ and $\left.\dot{m}_{w}\right)$. Based on the inputs and system-specific parameters, the air outlet enthalpy, $h_{a, o}$, and water outlet temperature, $T_{w, o}$, are predicted via equations of the form shown in Eqs. (7) and (8) [39].

$h_{a, o}=\frac{(1-r)}{(\Gamma-r)} h_{a, i}+\frac{(\Gamma-1)}{(\Gamma-r)} \phi T_{w, i}$

$T_{w, o}=\frac{\frac{(\Gamma-1) r}{(\Gamma-r)} h_{a, i}}{\phi}+\frac{(1-r)}{(\Gamma-r)} T_{w, i}$

Where:

$\Gamma=\exp \left(-\beta\left(\frac{1}{C_{w}}-\frac{1}{C_{a}}\right)\right) ; r=\frac{C_{a}}{C_{w}}$ 
Furthermore:

$C_{a}=\dot{m}_{a} ; C_{w}=\frac{C_{p, w} \dot{m}_{w}}{\phi} ; \phi=\frac{h_{s}}{T_{s}}$

From Eqs. (7) and

(8), the symbol $\beta$ represents the inverse of the overall thermal resistance of the direct contact heat transfer device (cooling tower or air cooler) and can be obtained by minimising the sum of the squares of the prediction errors in relation to manufacturers' data or a set of system measurements containing $N$ data points as show in Eq. (9) [39]. The air outlet temperature can also be determined with Eq. (10) [39].

$\beta_{\text {min }}=\operatorname{MIN} \sum_{k=1}^{N}\left(T_{w, o, \text { calc }, k}-T_{w, o, \text { real }, k}\right)^{2}$

$T_{a, o}=\frac{\left(T_{a, i}-T_{w, i}\right)}{\left(h_{a, i}-\phi T_{w, i}\right)} h_{a, o}+T_{a, i}-\frac{\left(T_{a, i}-T_{w, i}\right)}{\left(h_{a, i}-\phi T_{w, i}\right)} h_{a, i}$

\subsection{Pumps and Fans}

The evaporators, condensers, PCTs, BACs and circulation pumps have combined sub-system installed power ratings of $660 \mathrm{~kW}, 960 \mathrm{~kW}, 140 \mathrm{~kW}, 225 \mathrm{~kW}$ and $80 \mathrm{~kW}$ respectively while the total fan power of the PCTs and CCTs consist of $210 \mathrm{~kW}$ and $495 \mathrm{~kW}$ respectively. The BAC fan power was not considered as this is governed by the mines main ventilation fan as mentioned previously. The efficiency of the pump arrangements inclusive of the electrical motors $\eta_{m, p}$ was assumed as 0.8 while the combined fan and fan motor efficiency $\eta_{m, f}$ was 
assumed to be 0.75 . These values relate to typical manufacturer data for similar pumps and fans.

Pumps and fans were modelled by using Eq. (11) [39] to determine the power consumption $\dot{W}_{p / f}$ at given water or air flow rates.

$\dot{W}_{p / f}=\frac{\Delta P \cdot \dot{m}_{w / a}}{\rho \eta_{m, p / f}}$

Where $\dot{m}_{w / a}$ is the mass flow rate of the fluid considered, $\rho$ is the average fluid density and $\eta_{m, p / f}$ is the efficiency of the complete pump or fan arrangement inclusive of the motors. The simplified equation for the pressure differential over the pump, Eq. (14), is derived through simplification of the Darcy Weishbach equation, Eq. (12) as shown below [40].

$\Delta P=\left(\frac{10^{6} f L}{D_{h}}+\sum C\right)\left(\frac{\rho V^{2}}{2}\right)$

By replacing the average velocity $(V)$ with $\frac{\dot{m}}{\rho A}$, the equation can be rewritten as Eq. (13).

$\Delta P=\left(\frac{10^{6} f L}{D_{h}}+\sum C\right)\left(\frac{\dot{m}^{2}}{2 \rho A^{2}}\right)$

Eq. (13) can be simplified by assuming constant values for the friction factor $(f)$, characteristic length $(L)$, the characteristic diameter $\left(D_{h}\right)$ and the flow passage cross sectional area $\left(A^{2}\right)$ for each sub-system containing a pump or fan. By doing so, Eq. (13) reduces to Eq. (14). 
$\Delta P=\frac{\dot{m}_{w / a}^{2}}{k \rho}$

Where $k$ is the flow admittance, it may be assumed to be constant for the range of flow rate conditions considered and can be determined through only a single point measurement or theoretical calculation [41]. Du Plessis et al. [2] successfully implemented this simplified form of the Darcy Weishbach equation as part of their models.

\section{Models Parameters Determination and Validation}

The models proposed in the previous section were calibrated and validated with system data obtained from the mine's SCADA system. This was achieved by programming the various equations into Microsoft Office Excel for each of the cooling system components respectively. The various component specific parameters were then obtained by using the Excel integrated solver function in conjunction with Eqs (2), (6) and (9) along with the relevant measured mine cooling system data.

Because mining operations are running continuously during the week with reduced operation over the weekends, it was more practical to use only weekdays and therefore one continuous typical summer week's data was isolated as dataset A while the two weekends before and after were omitted from the data. Dataset A was used for the sub-system simulation model calibration, referred to as parameter determination throughout this paper, in this section as well as the first integrated model simulation and validation in Section 5. Later in the paper a second typical summer week's data, dataset B, one month after dataset A was used to determine the models simulation accuracy outside the sub-system parameter determination data period. 
For the purposes of these sub-system validations, only the chiller and cooling tower models are considered. The pump and fan power models are incorporated into the integrated system validation later in the paper, where the modelled total system power will be validated against the measured total system power. This approach was followed as these components' thermal hydraulic and power data was not separately available on the mine's logged SCADA system, but was rather incorporated along with the total plant energy consumption data as these were measured at the main electrical feeders to the plant. Furthermore, the pump and fan coefficients were determined by the manufacture specifications provided, from where the model proposed earlier was used to determine the power consumption at partial flow conditions.

The simulation accuracy of the various sub system models were calculated using the RootMean-Square of Relative Error (RMSRE) as an error index and can be computed by Eq. (15). [42].

$R M S R E=\sqrt{\frac{\sum_{k=1}^{n}\left(\frac{\tau_{\text {real }, k}-\tau_{\text {sim }, k}}{\tau_{\text {real }, k}}\right)^{2}}{n}}$

Where $\tau_{\text {real }}$ represents the measured parameter value and $\tau_{\text {sim }}$ the simulated value for the same parameter.

\subsection{Refrigeration plant model parameter identification and validation}

The refrigeration plant model parameters as proposed in Section 3.1 were obtained and validated with Dataset A as described earlier. This data was used to simulate the cooling 
capacity and coefficient of performance of the chiller machines with Eqs. (1) and (5) as the system parameters change dynamically throughout each day of the week. To determine the coefficient of performance parameters $\left(\sigma_{0}\right.$ to $\left.\sigma_{9}\right)$ the entire dataset was used, while the dataset was filtered to include only above $98 \%$ vane opening (or full load) operation for the determination of the parameters $\left(c_{1}, c_{2}\right.$ and $\left.c_{3}\right)$ for the cooling capacity as stated earlier. As a result, all partial-load operation data was eliminated from the dataset in order to capture the effect of the varying evaporator and condenser temperature on the cooling performed at full load only.

The coefficient of performance parameters were determined and the results for $\sigma_{0}$ to $\sigma_{9}$ of Eq. (5) as shown in Table 3 were obtained. For this parameter identification, a RMSRE value of 0.0114 was achieved between the measured and simulation COP. All the data-points fall within the $10 \%$ error band, while $99.4 \%$ of the data points fall within the $5 \%$ error band. The average absolute error is $0.75 \%$. The correlation accuracy obtained here suggests the accuracy by which Eq. (5) represents the COP of the cooling system under consideration. For comparison, the coefficient of variation as used by Lee and $\mathrm{Lu}$ [34] was also considered for the COP and found to be $1.12 \%$. This corresponds well with the range obtained by Lee and $\mathrm{Lu}$ [34] where coefficient of variation values in the range of $0.25 \%$ to $3.51 \%$ were found.

The cooling capacity parameters were determined in a similar fashion with the values for $c_{1}, c_{2}$ and $c_{3}$ of Eq. (1) as shown in Table 3; with a RMSRE value of 0.0197 between the measured and simulated $\mathrm{CC}$, with all data-points remaining inside the $10 \%$ error band while $97.9 \%$ of the datapoints remained inside the $5 \%$ error band. The average absolute error is 1.49\%. This suggests the accuracy by which Eq. (1) represents the CC of the cooling system. The cooling capacity and coefficient of performance were calculated only for one of the 
chiller machines as there was only one machine that ran continuously for the dataset considered. These correlations are then assumed for all six chillers as part of the integrated system simulation performed later on. The correlations for the parameter determination of the coefficient of performance (COP) and cooling capacity (CC) can be seen in Error! Reference source not found. and Error! Reference source not found. respectively.

Table 3 COP and $C C$ Model Parameters

\begin{tabular}{|c|c|c|c|}
\hline COP Parameter & Value & CC Parameter & Value \\
\hline$\sigma_{0}$ & $3.251 E+01$ & $c_{1}$ & $9.562 E+03$ \\
\hline$\sigma_{1}$ & $-2.573 E-03$ & $c_{2}$ & $4.052 E+02$ \\
\hline$\sigma_{2}$ & $1.674 E-02$ & $c_{3}$ & $-2.067 E-02$ \\
\hline$\sigma_{3}$ & $-1.393 E+00$ & & \\
\hline$\sigma_{4}$ & $3.639 E-08$ & & \\
\hline$\sigma_{5}$ & $5.435 E-03$ & & \\
\hline$\sigma_{6}$ & $1.585 E-02$ & & \\
\hline$\sigma_{7}$ & $3.721 E-05$ & & \\
\hline$\sigma_{8}$ & $8.615 E-05$ & & \\
\hline$\sigma_{9}$ & $-1.546 E-02$ & & \\
\hline
\end{tabular}




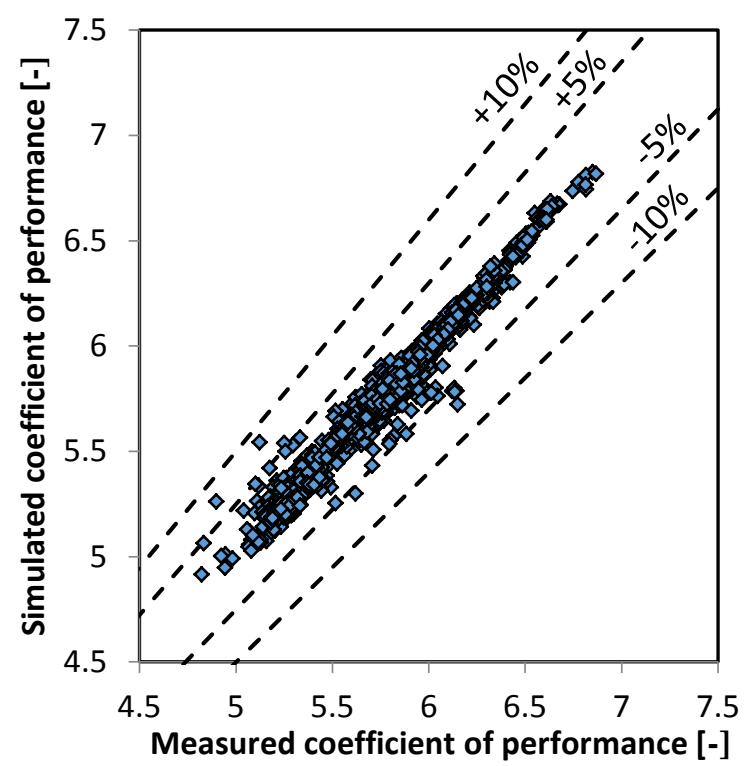

Figure 3: Chiller measured and simulated coefficient of performance correlation

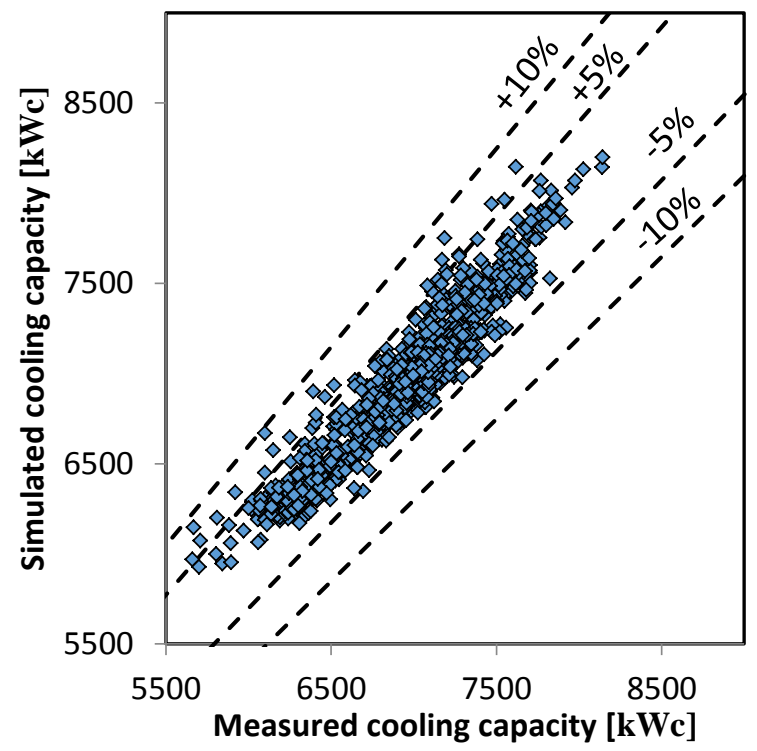

Figure 4: Chiller measured and simulated cooling capacity correlation

Figure 5 and Figure 6 shows the measured and simulated values of the coefficient of performance and cooling capacity respectively for the one-week period of dataset A. 


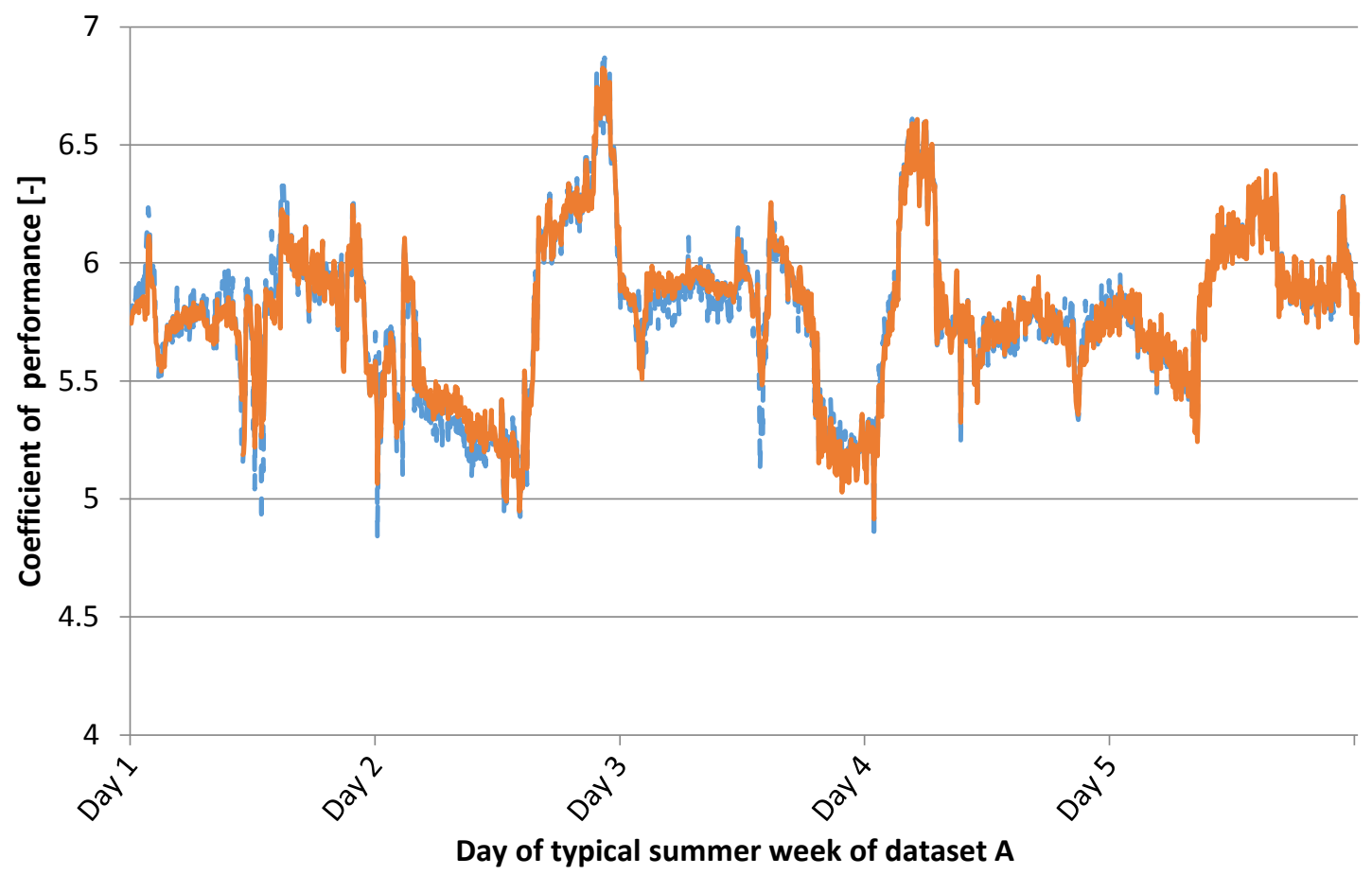

- - - Measured chiller coefficient of performance Simulated chiller coefficient of performance

Figure 5 Chiller measured and simulated coefficient of performance for typical summer week of dataset A

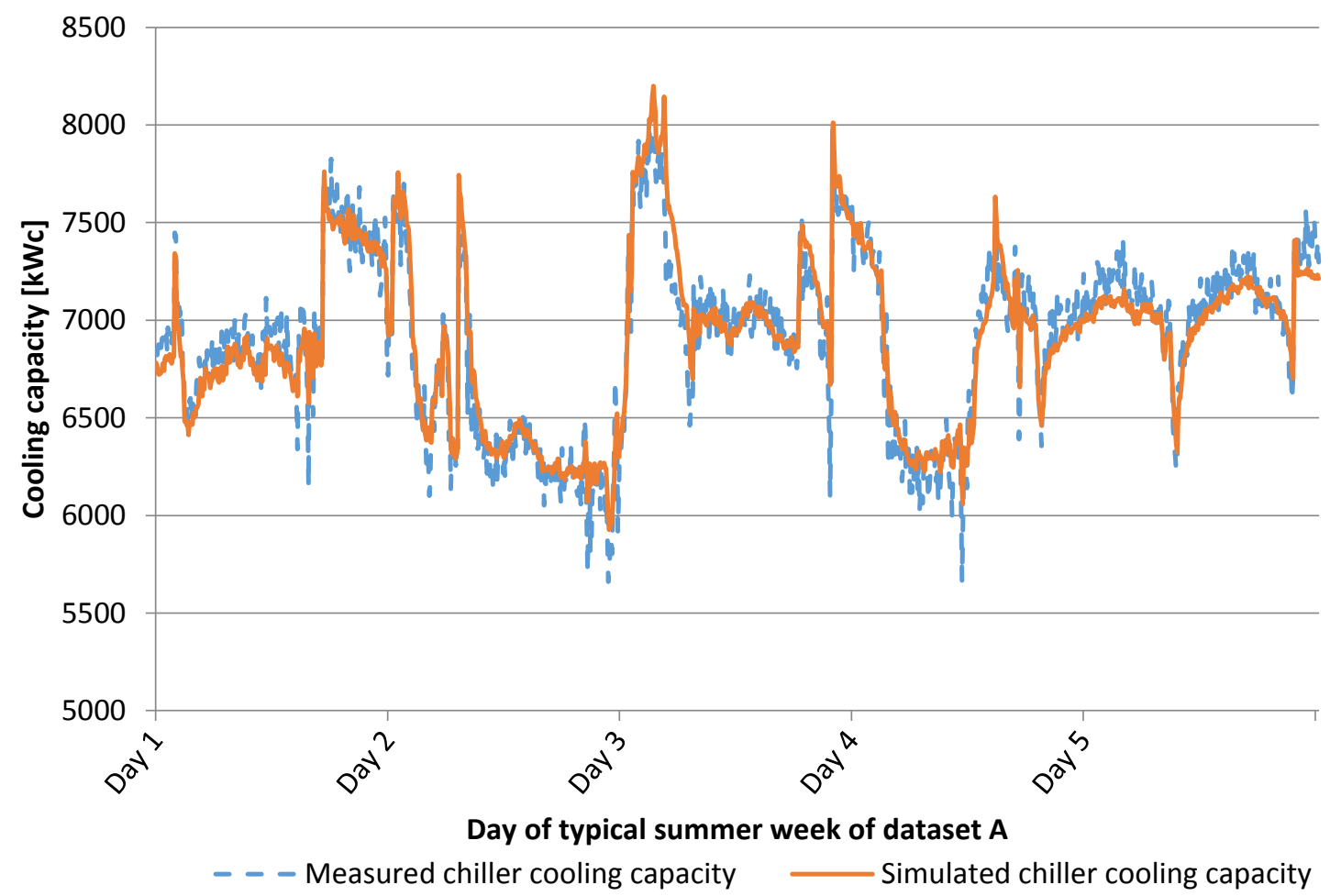

Figure 6 Chiller measured and simulated cooling capacity for typical summer week of dataset A 


\subsection{Cooling Towers and Air Coolers Model Parameter Identification and Validation}

The cooling tower model parameters $\beta_{P C T}, \beta_{B A C}$ and $\beta_{C C T}$ for the PCTs, BACs and CCTs respectively as shown in Figure 1 and described in Section 3.2 were determined for dataset A. Eq. (8) was used to simulate the water outlet temperatures of the various cooling towers and the bulk air coolers.

\section{Pre-cooling Towers}

The pre-cooling tower model parameter was determined to be $\beta_{P C T}=655.12 \mathrm{~W} / \mathrm{K}$. For this parameter determination a RMSRE value of 0.0651 was achieved between the measured and simulation water outlet temperatures with the simulated water outlet temperature remaining inside the $1{ }^{\circ} \mathrm{C}$ error band for $66.24 \%$ and inside the $2{ }^{\circ} \mathrm{C}$ error band for $89.61 \%$ of the time, while the average absolute error obtained was $0.87{ }^{\circ} \mathrm{C}$ when compared to the measured water outlet temperature. This suggests the accuracy of Eq. (8) when calibrated according to the pre-cooling tower of the cooling system considered. This result correlate well with that found in literature as RMSRE values ranging between 0.052 and 0.099 were obtained on the water outlet temperature prediction of an air cooler previously [39].

The correlation between the measured and simulated water outlet temperature for the parameter determination of the pre-cooling tower can be seen in Figure 7. 


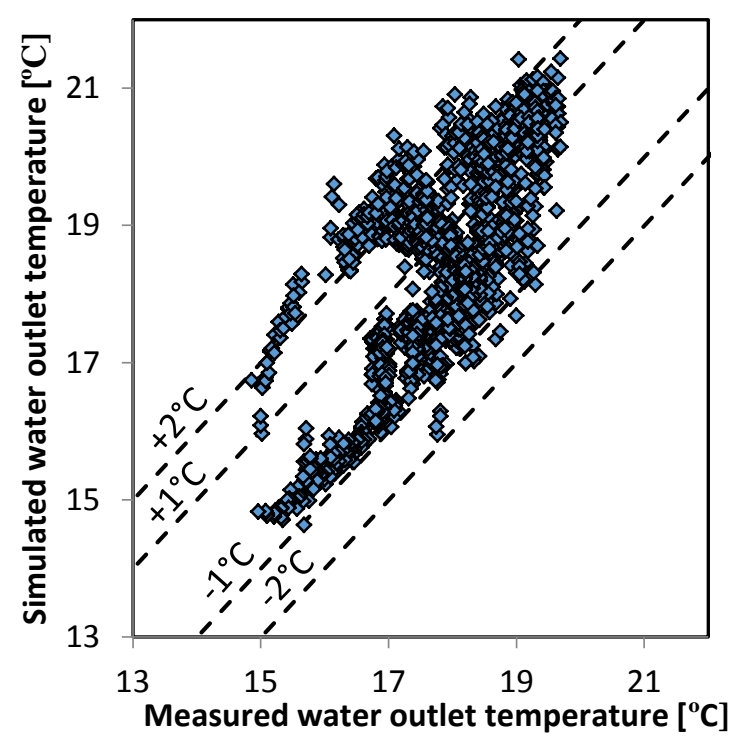

Figure 7 Pre-cooling tower measured and simulated water outlet temperature correlation

Figure 8 shows the measured and simulated values of the pre-cooling tower water outlet temperature respectively for the one-week period of dataset A. From these graphs it can be seen that the simulation model slightly under-predicts the water outlet temperature prematurely to the measured water outlet temperature with respect to the cooling performed on the water. This shows that the pre-cooling towers reaction time to dynamic changes in the system is slower in reality than what is proposed by the simulation model. 


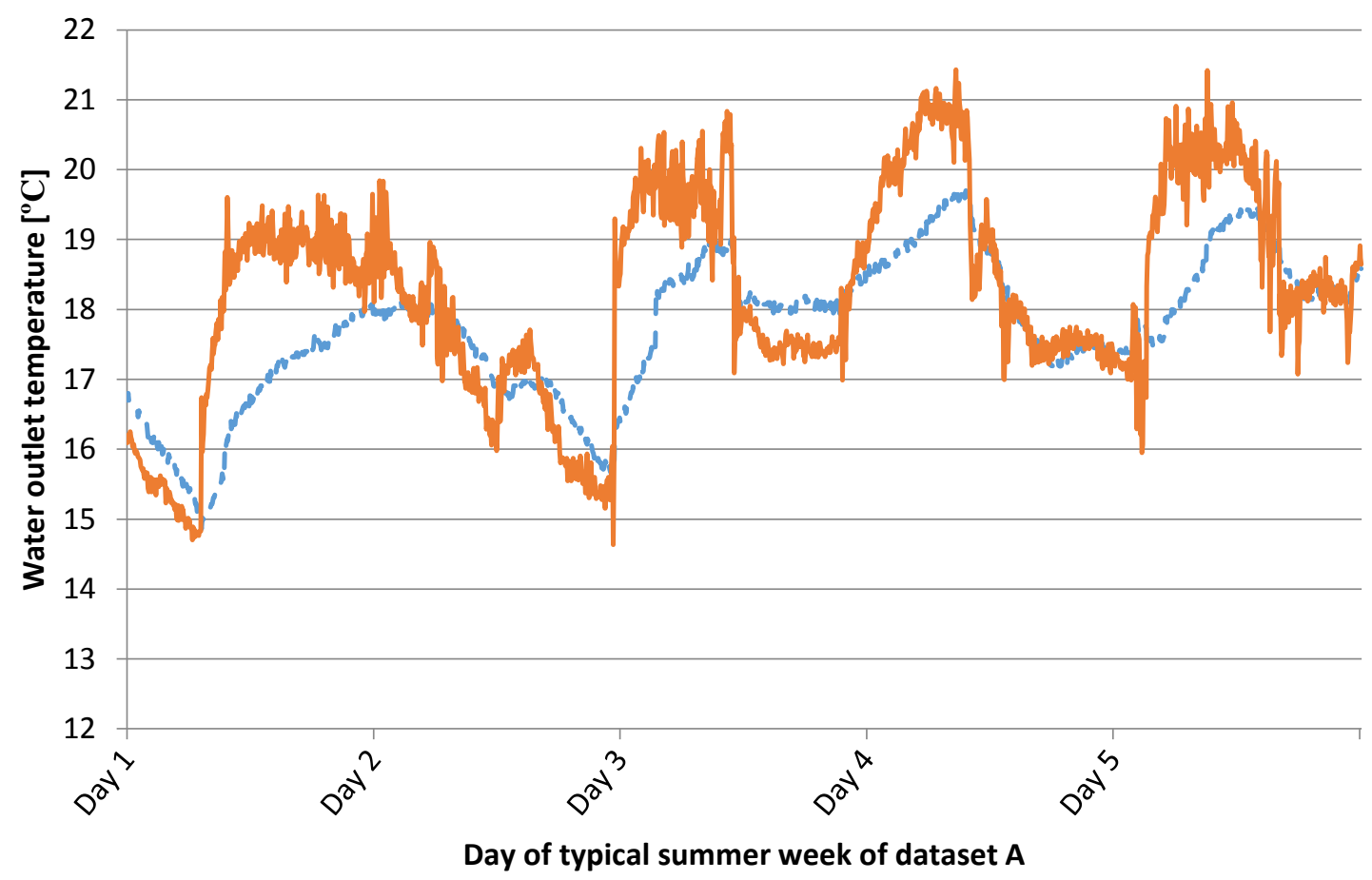

- - - Measured water outlet temperature

Simulated water outlet temperature

Figure 8 Pre-cooling tower measured and simulated water outlet temperature for typical summer week of dataset A

\section{Bulk Air Coolers}

Due to the BAC water outlet temperature $T_{w, o, B A C}$ and air flow rate $\dot{m}_{a, B A C}$ not being directly measured, they had to be calculated from the SCADA's logged system data. The BAC water outlet temperature can be calculated through an energy balance over the pre-cooling dam as shown in Eq. (16) [39]; by assuming that the specific heat capacity of the water $C_{p, w}$ remains constant for the temperature range considered; that there is insignificant evaporation loss from the pre-cool dam and that the pre-cooling dam and all pipes to and from the dam are adiabatic as stated earlier. 


$$
\begin{aligned}
& T_{w, o, B A C} \\
& =\frac{\dot{m}_{w, \text { evap }} \cdot T_{w, i, \text { evap }}-\dot{m}_{w, \text { mine }} \cdot T_{w, o, P C T}-\left(\dot{m}_{w, \text { evap }}-\dot{m}_{w, \text { mine }}-\dot{m}_{w, B A C}\right) \cdot T_{w, o, \text { evap }}}{\dot{m}_{w, B A C}}
\end{aligned}
$$

From here, the BAC air flow rate $\dot{m}_{a, B A C}$ can be calculated by utilising the energy balance principle in the BAC as given in Eq. (17) [39].

$$
\dot{m}_{a, B A C}=\frac{C_{p, w} \cdot \dot{m}_{w, B A C}\left(T_{w, o, B A C}-T_{w, o, e v a p}\right)}{h_{a, A M B}-h_{a, o, B A C}}
$$

With all the required system parameters available, the BAC model parameter was determined to be $\beta_{B A C}=835.19 \mathrm{~W} / \mathrm{K}$. For this parameter determination, a RMSRE value of 0.0648 was achieved between the measured and simulated water outlet temperatures with the simulated water outlet temperature remaining inside $1{ }^{\circ} \mathrm{C}$ of the measured temperatures $81.58 \%$ of the time; whilst the average absolute error obtained was $0.5^{\circ} \mathrm{C}$ when compared to the measured water outlet temperature. This accuracy suggests the accuracy of Eq. (8) when calibrated according to the BAC of the cooling system. Similarly to the pre-cooling tower, the result obtained here correlate well with that found in literature where RMSRE values ranging between 0.052 and 0.099 were obtained on a similar device before [39].

The correlation between the measured and simulated water outlet temperature for the parameter determination of the BAC can be seen in Figure 9. 


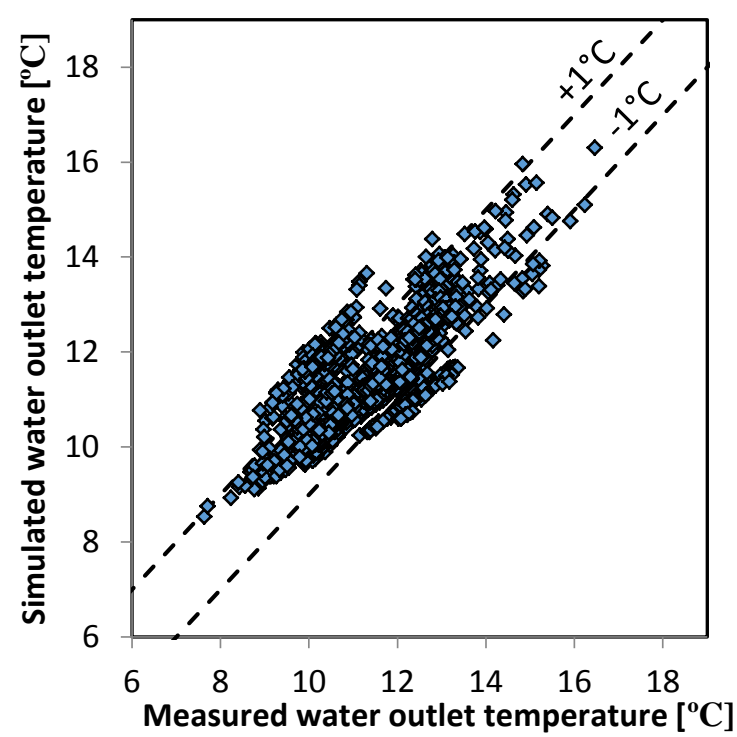

Figure 9 Bulk air cooler measured and simulated water outlet temperature correlation

Figure 10 shows the measured and simulated values of the BAC water outlet temperature respectively for the one-week period of dataset A. From this graph it is evident that the measured BAC water outlet temperature fluctuates significantly. It can also be seen that the simulated outlet temperature follows the measured outlet temperature even in the event of significant fluctuation in the measured data. 


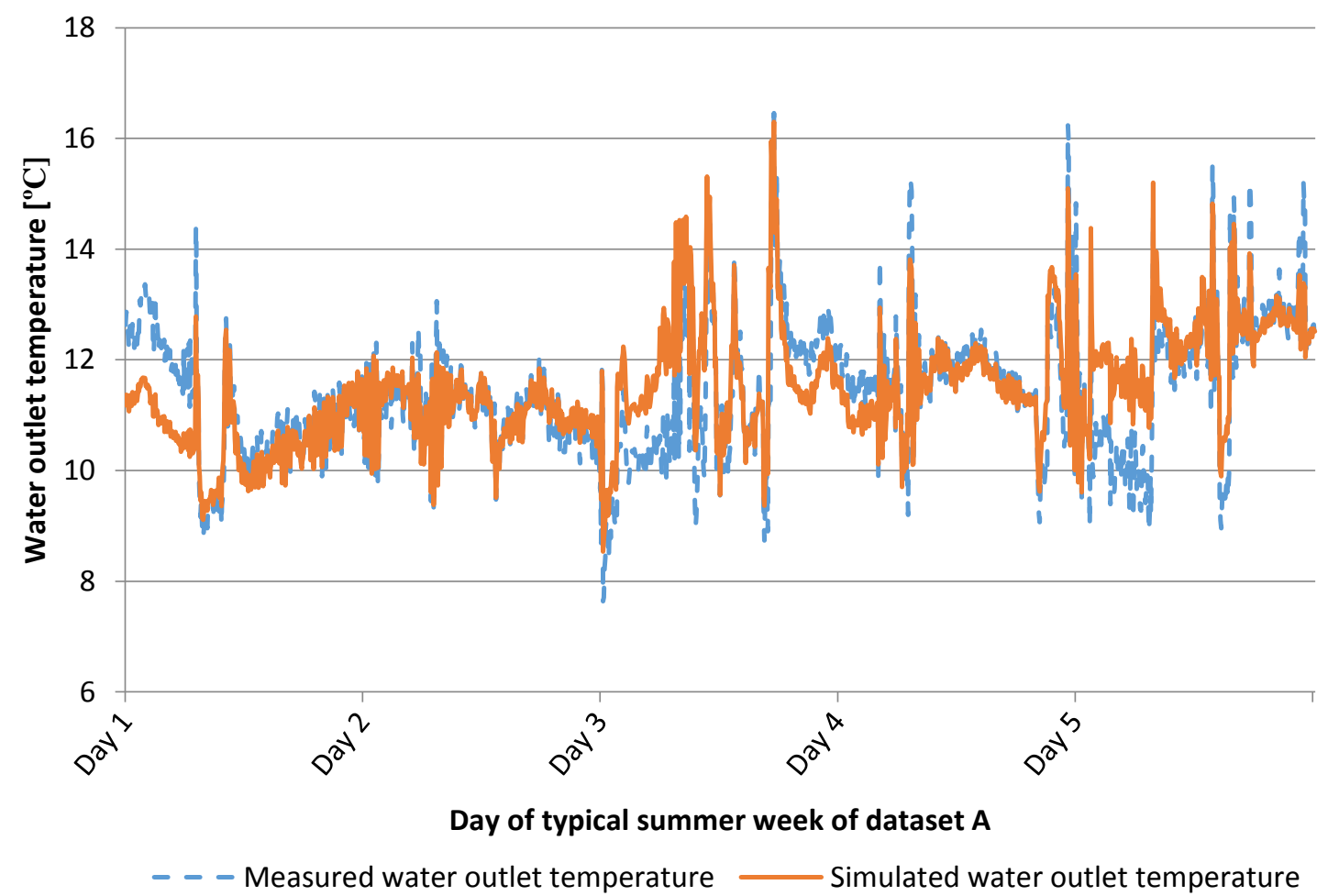

Figure 10 Bulk air cooler measured and simulated water outlet temperature for typical summer week of dataset A

\section{Condenser Cooling Towers}

The condenser cooling tower model parameter was determined to be $\beta_{C C T}=234.98 \mathrm{~W} / \mathrm{K}$. For this parameter determination, a RMSRE value of 0.0246 was achieved between the measured and simulated water outlet temperatures with the simulated water outlet temperature remaining inside $1{ }^{\circ} \mathrm{C}$ error $90.07 \%$ of the time; whilst the average absolute error obtained was $0.48{ }^{\circ} \mathrm{C}$. This suggests the accuracy of Eq. (8) when calibrated for to the condenser cooling tower of the cooling system under consideration. The result obtained here correlate well with similar results found in literature where RMSRE values ranging between 0.052 and 0.099 were achieved [39]. 
The correlation between the measured and simulated water outlet temperature for the parameter determination of the condenser-cooling tower can be seen in Figure 11.

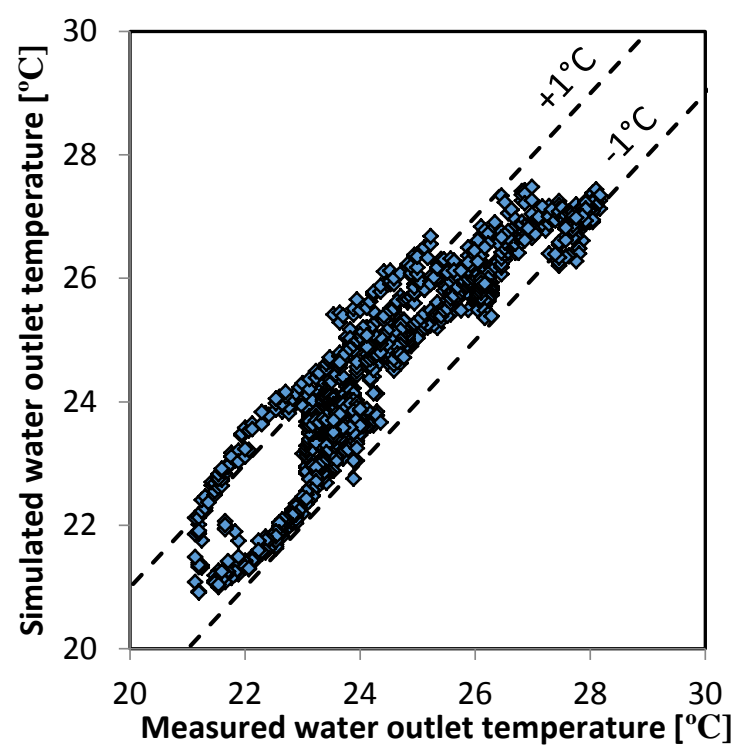

Figure 11 Condenser cooling tower measured and simulated water outlet temperature correlation

Figure 12 shows the measured and simulated values of the condenser cooling tower water outlet temperature respectively for the one-week period of dataset A. 


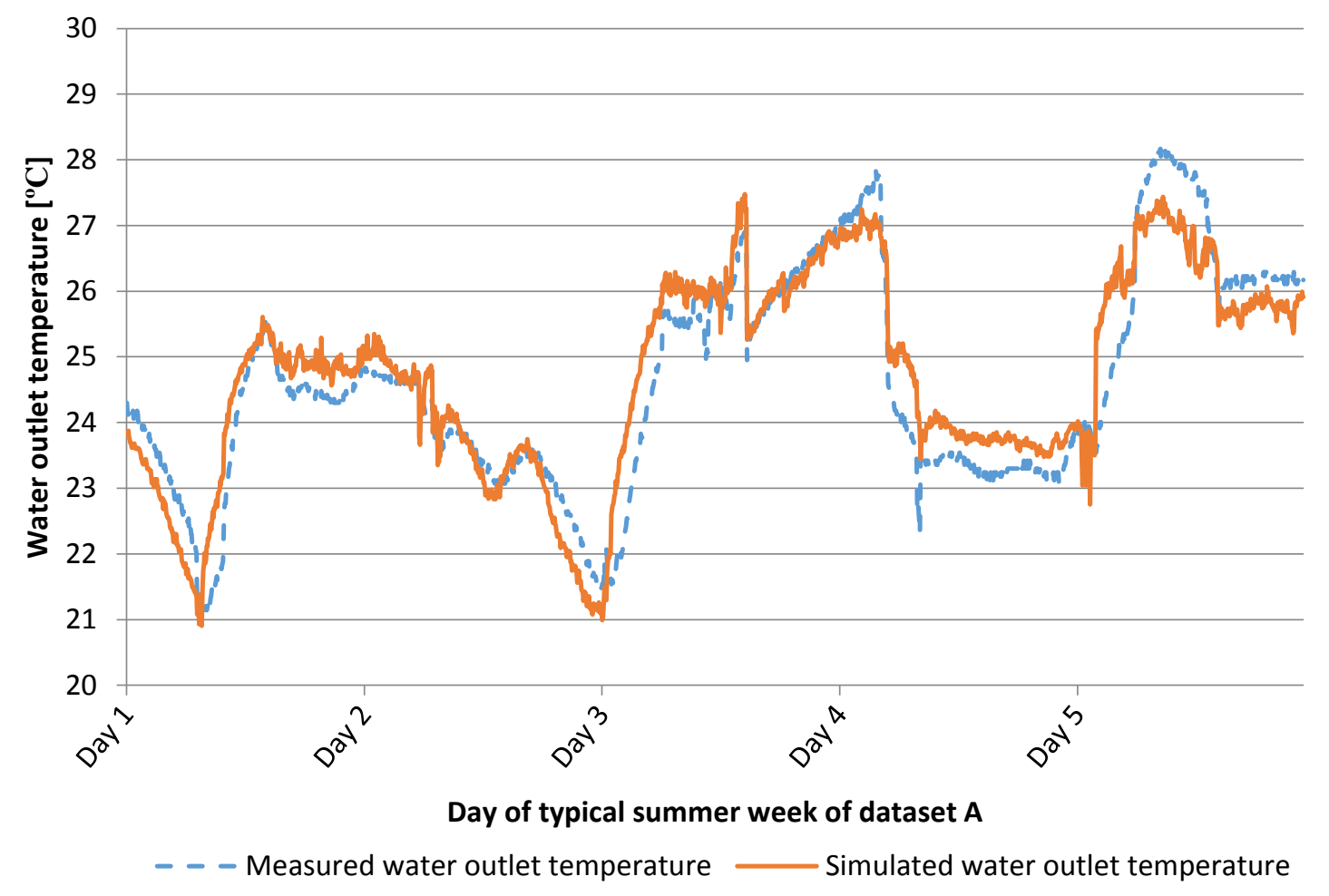

Figure 12 Condenser cooling tower measured and simulated water outlet temperature for typical summer week of dataset $\mathrm{A}$

\section{Integrated System Validation}

The total power consumption of the system under consideration includes the power consumption of the compressors of the chiller machines; the evaporator and condenser pumps; the PCT, BAC, CCT and circulation pumps; and fans as portrayed in Eq. (18).

$$
\begin{aligned}
\dot{W}_{\text {plant }, \text { sim }}= & \dot{W}_{\text {ref }}+\dot{W}_{f, P C T}+\dot{W}_{f, C C T}+\dot{W}_{p, P C T}+\dot{W}_{p, B A C}+\dot{W}_{p, \text { cond }} \\
& +\dot{W}_{p, \text { evap }}+\dot{W}_{p, \text { cir }}
\end{aligned}
$$

In order to evaluate the integrated simulation accuracy of the complete cooling system consisting of the various component models, described in Section 3 of this paper, the cooling system of the mine considered as illustrated in Figure 1 was used. The various models' 
parameters as determined in Section 4 were used for the cooling towers and chiller machines, while Eq. (14) along with the manufacturer data were used to determine the flow admittance values $k$ and corresponding pressure differentials for the various pumps and fans as indicated by the values in Table 4. Dataset A was first used for the integrated simulation and Dataset B was subsequently used to determine the simulation model's behaviour one month away from the training data as mentioned earlier.

Table 4 Pumps and fans pressure differential and admittance values

\begin{tabular}{|l|l|l|}
\hline Component & Pressure differential, $\Delta \boldsymbol{P}[\mathbf{k P a}]$ & Admittance value, $\boldsymbol{k}\left[\mathbf{m}^{4}\right]$ \\
\hline Evaporator Pump & 352 & 5.63 \\
\hline Pre-cooling tower pump & 311 & 2.40 \\
\hline Pre-cooling tower fan & 0.3 & $4.22 \mathrm{E}-07$ \\
\hline BAC pump & 240 & 3.84 \\
\hline Circulation pump & 178 & 1.37 \\
\hline Condenser pump & 284 & 1.40 \\
\hline Condenser fan & 0.28 & $5.49 \mathrm{E}-06$ \\
\hline
\end{tabular}

The complete system was simulated by assigning the outlet condition's set-point of each component according to the measured data by simulating mass flow and component inletand outlet-temperatures as measured. This ensured that the system thermal performance was fully coordinated with the measured data, while the power predicted by the simulation model will vary in accordance to the integrated component modelling accuracy.

\section{Results}

The simulation's total system power was compared with the measured power as obtained from the mine's SCADA system for dataset A as shown in Figure 13. From this figure, it is 
evident that the simulated power follows the measured power closely. The average absolute error obtained by the simulation was $3.52 \%$; comparing well with result obtained by $\mathrm{Du}$ Plessis et al. [2] where a mine cooling system was simulated with an average error of $4.1 \%$, while Wei et al. [43] obtained average errors up to $4.3 \%$ on HVAC system optimisation simulations. From the graph, it is evident that the model tends to under-predict the power at higher total system power when more chiller machines are operational; while the simulation slightly over-predicts the power for lower total system power. In order to justify the significant step changes in power consumption, the number of chiller machines operational at any given point in time is super-imposed on this graph on the secondary axis. The total chiller evaporator water flow rate is also included on the secondary axis and relates closely to the overall power consumption as well as the number of chillers in operation. The ambient air enthalpy is lastly included in this figure in order to identify the system behaviour towards fluctuations in the climate conditions. It is visible that the water flow rate has a closer representation to the overall power consumption than the ambient air enthalpy. 


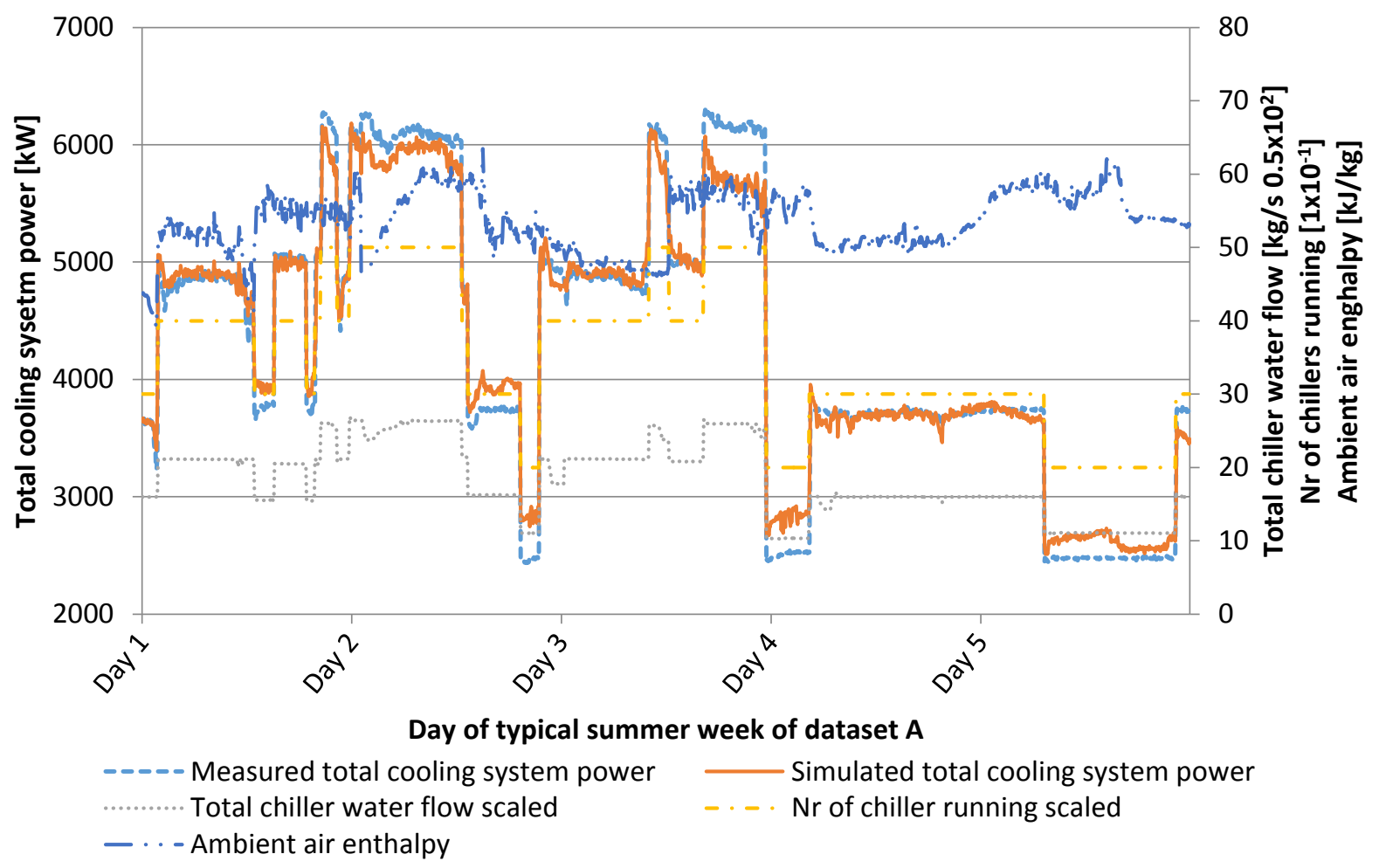

Figure 13 Total cooling system measured and simulated power consumption for typical summer week of dataset A

Dataset B was similarly used to simulate the mine cooling systems integrated energy consumption for the one week period. The results are shown in Figure 14 from where it can be seen that the simulated power still follows the measured system power closely. It is also evident that, similarly to dataset A, the model tends to slightly under-predict the power when more machines are running (first part of Day 3) and over-predict for fewer machines as can be seen for Day 5. This simulation achieved an average absolute error of $2.53 \%$ which is an improvement on the results obtained for dataset A. The improvement on the model accuracy could be ascribed to the fact that the plant's operation was more continuous with less fluctuation in the number of chiller machines in operation as can be seen in Figure 14 when compared to Figure 13. Similar to dataset A, the total chiller evaporator water flow rate is also included on the secondary axis and again relates closely to the overall power consumption and the number of chillers in operation. The ambient air enthalpy is included to 
identify the system behaviour towards fluctuations in the climate conditions. It is evident that the water flow rate has a closer representation to the overall power consumption than the ambient air enthalpy, although the significant reduction in power consumption during day five could be due to the noticeable reduction in the ambient enthalpy for the period.

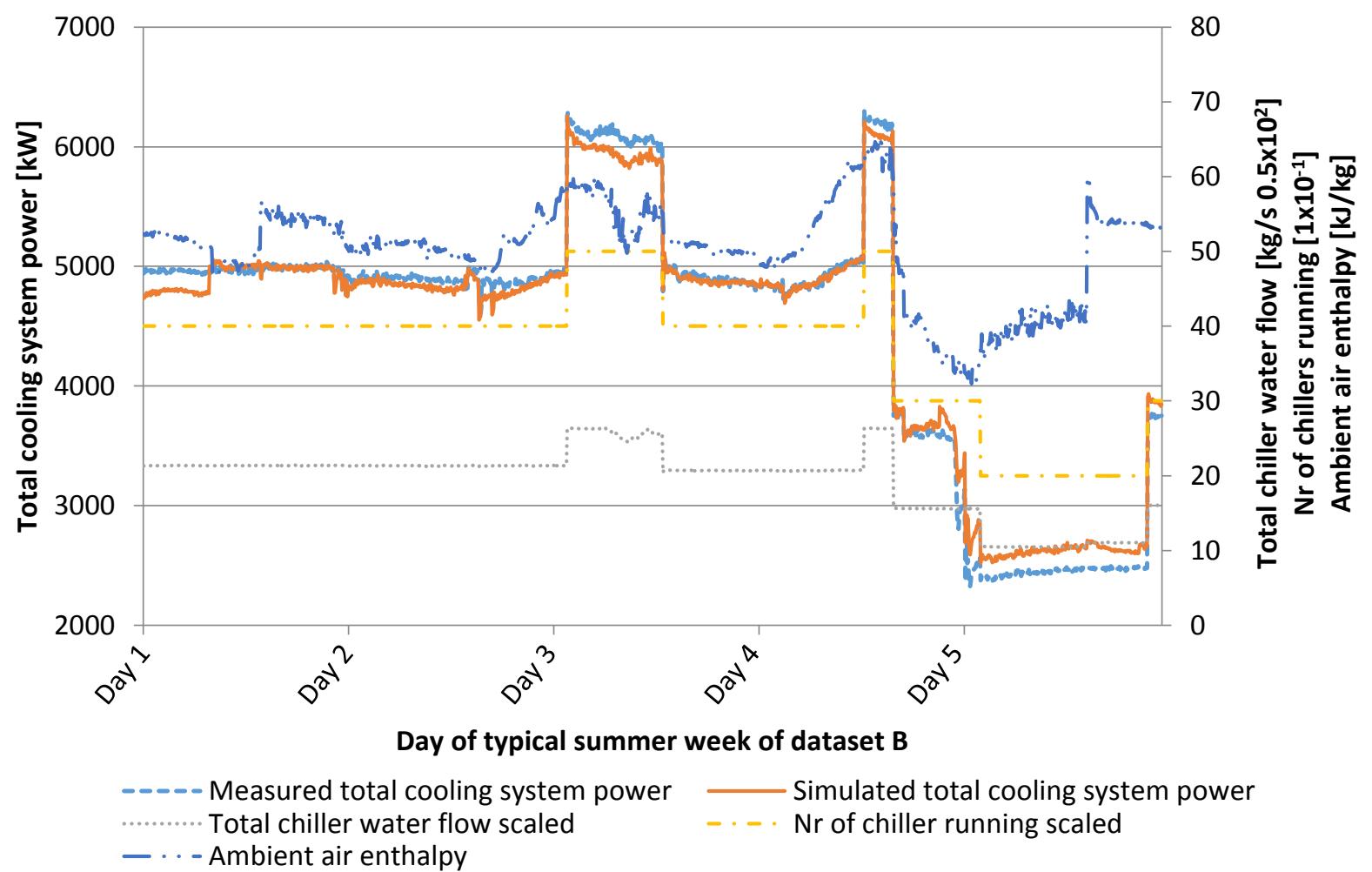

Figure 14 Total cooling system measured and simulated power consumption for typical summer week of dataset B

\section{Conclusion}

An explicit, integrated energy simulation model for a deep level gold mine cooling system was developed in the study. The method presented is based on coupling suitable sub-system models together, which represent the major components of the cooling system. The integrated effect of thermal hydraulic variances in any component can be simulated as it influences the system behaviour and energy consumption. Each component's model requires 
system specific calibration coefficients that could be obtained either by on-site system measurements or manufacturer data.

The sub-system component models do not consider all physical parameters of each subsystem as the objective was to construct a model that will simulate the energy consumption through variances in the thermal hydraulic behaviour and consequently these models were chosen accordingly. The parameter identification of the various models achieved RMSRE values in the range of 0.0114 to 0.0651 for the mine cooling system considered. RMSRE values less than 0.1 are considered acceptable for engineering design purposes Jin et al. [42].

The integrated simulation model was firstly used to simulate the performance and energy consumption of the mine cooling system for one typical summer week and achieved an accuracy with an average absolute error of $3.52 \%$ on the total system energy consumption compared to the measured data. Dataset B containing data one month after the simulation model's parameter determination data, dataset A, was used to confirm the model's accuracy outside the training data and achieved an improved accuracy with an average absolute error of $2.53 \%$. The objective of the study was achieved as the model constructed was able to predict the system energy consumption of the integrated mine cooling system.

The successful integrated energy modelling of the mine cooling system would allow further opportunity to investigate the effect of various external parameter variations to the plant and its effect on the overall power consumption. It would also facilitate the opportunity to incorporate the model into an optimisation platform for overall integrated system energy minimisation. 


\section{Acknowledgements}

The mine for the cooling system data.

Sunél Bornman for proof reading the manuscript

\section{Bibliography}

[1] W. Bornman, Improved mine cooling system performance through the control of auxiliary systems, M-Eng Dissertation, North-West University, Potchefstroom, South Africa, 2012.

[2] G.E. Du Plessis, D.C. Arndt, E.H. Mathews, The development and integrated simulation of a variable water flow energy saving strategy for deep-mine cooling systems, Sustain. Energy Technol. Assessments. 10 (2015) 71-8. doi:10.1016/j.seta.2015.03.002.

[3] J. Van Rensburg, A. Botha, G. Bolt, Energy efficiency via optimisation of water reticulation in deep mines, in: Ind. Commer. Use Energy, 2011: pp. 124-32.

[4] A.J. Gunson, B. Klein, M. Veiga, S. Dunbar, Reducing mine water network energy requirements, J. Clean. Prod. 18 (2010) 1328-1338. doi:10.1016/j.jclepro.2010.04.002.

[5] J. Vosloo, L. Liebenberg, D. Velleman, Case study : Energy savings for a deep-mine water reticulation system, Appl. $\quad$ Energy. $92 \quad$ (2012) 328-335. doi:10.1016/j.apenergy.2011.10.024.

[6] A.J. Schutte, Demand-side energy management of a cascade mine surface refrigeration system, M-Eng Dissertation, North-West University, South Africa, 2007.

[7] G.E. Du Plessis, L. Liebenberg, E.H. Mathews, J.N. Du Plessis, A versatile energy management system for large integrated cooling systems, Energy Convers. Manag. 66 (2013) 312-25. doi:10.1016/j.enconman.2012.12.016.

[8] G.E. Du Plessis, L. Liebenberg, E.H. Mathews, The use of variable speed drives for costeffective energy savings in South African mine cooling systems, Appl. Energy. 111 (2013) 16-27. doi:10.1016/j.apenergy.2013.04.061. 
[9] G.E. du Plessis, L. Liebenberg, E.H. Mathews, Case study: The effects of a variable flow energy saving strategy on a deep-mine cooling system, Appl. Energy. 102 (2013) 700-9. doi:10.1016/j.apenergy.2012.08.024.

[10] J.A. Romero, J. Navarro-Esbrí, J.M. Belman-Flores, A simplified black-box model oriented to chilled water temperature control in a variable speed vapour compression system, Appl. Therm. Eng. 31 (2011) 329-35. doi:10.1016/j.applthermaleng.2010.09.013.

[11] K.-P. Lee, T.-A. Cheng, A simulation-optimization approach for energy efficiency of chilled water system, Energy Build. $54 \quad$ (2012) 290-296. doi:10.1016/j.enbuild.2012.06.028.

[12] J. Hu, P. Karava, A state-space modeling approach and multi-level optimization algorithm for predictive control of multi-zone buildings with mixed-mode cooling, Build. Environ. 80 (2014) 259-273. doi:10.1016/j.buildenv.2014.05.003.

[13] Z. Ma, S. Wang, An optimal control strategy for complex building central chilled water systems for practical and real-time applications, Build. Environ. 44 (2009) 1188-98. doi:10.1016/j.buildenv.2008.08.011.

[14] X. Li, Y. Li, J.E. Seem, P. Li, Dynamic modeling and self-optimizing operation of chilled water systems using extremum seeking control, Energy Build. 58 (2013) 172-82. doi:10.1016/j.enbuild.2012.12.010.

[15] N. Liang, S. Shao, C. Tian, Y. Yan, Dynamic simulation of variable capacity refrigeration systems under abnormal conditions, Appl. Therm. Eng. 30 (2010) 1205-14. doi:10.1016/j.applthermaleng.2010.01.038.

[16] M. Ali, V. Vukovic, M.H. Sahir, G. Fontanella, Energy analysis of chilled water system configurations using simulation-based optimization, Energy Build. 59 (2013) 111-22. doi:10.1016/j.enbuild.2012.12.011.

[17] F.W. Yu, K.T. Chan, Energy management of chiller systems with data envelopment analysis, Appl. $\quad$ Therm. $\quad$ Eng. $50 \quad$ (2013) 309-17. 
doi:10.1016/j.applthermaleng.2012.08.023.

[18] F.. Yu, K.T. Chan, Improved energy management of chiller systems by multivariate and data envelopment analyses, Appl. Energy. (2011) 168-74. doi:10.1016/j.apenergy.2011.11.016.

[19] T.T. Chow, K.F. Fong, A.L.S. Chan, R. Yau, W.H. Au, V. Cheng, Energy modelling of district cooling system for new urban development, Energy Build. 36 (2004) 1153-62. doi:10.1016/j.enbuild.2004.04.002.

[20] A. Aravelli, S.S. Rao, Energy optimization in chiller plants: A novel formulation and solution using a hybrid optimization technique, Eng. Optim. (2012) 1-17. doi:10.1080/0305215X.2012.725053.

[21] V. Vakiloroaya, Q.P. Ha, B. Samali, Energy-efficient HVAC systems: Simulationempirical modelling and gradient optimization, Autom. Constr. 31 (2013) 176-82. doi:10.1016/j.autcon.2012.12.006.

[22] Y. Li, J. Wu, S. Shiochi, Modeling and energy simulation of the variable refrigerant flow air conditioning system with water-cooled condenser under cooling conditions, Energy Build. 41 (2009) 949-57. doi:10.1016/j.enbuild.2009.04.002.

[23] N. Nassif, Modeling and optimization of HVAC systems using artificial neural network and genetic algorithm, Build. Simul. 7 (2013) 237-45. doi:10.1007/s12273-013-0138-3.

[24] Z.X. Jing, X.S. Jiang, Q.H. Wu, W.H. Tang, B. Hua, Modelling and optimal operation of a small-scale integrated energy based district heating and cooling system, Energy. 73 (2014) 399-415. doi:10.1016/j.energy.2014.06.030.

[25] G. liang Ding, Recent developments in simulation techniques for vapour-compression refrigeration systems, Int. J. Refrig. $30 \quad$ (2007) 1119-33. doi:10.1016/j.jirefrig.2007.02.001.

[26] A. Afram, F. Janabi-shari, Review of modeling methods for HVAC systems, Appl. Therm. Eng. 67 (2014) 507-19. doi:10.1016/j.applthermaleng.2014.03.055. 
[27] R.N.N. Koury, L. Machado, K.A.R. Ismail, Numerical simulation of a variable speed refrigeration system, Int. J. Refrig. 24 (2001) 192-200.

[28] T.T. Chow, G.Q. Zhang, Z. Lin, C.L. Song, Global optimization of absorption chiller system by genetic algorithm and neural network, Energy Build. 34 (2002) 103-9. doi:10.1016/S0378-7788(01)00085-8.

[29] K.F. Fong, V.I. Hanby, T.T. Chow, HVAC system optimization for energy management by evolutionary programming, Energy Build. $38 \quad$ (2006) 220-31. doi:10.1016/j.enbuild.2005.05.008.

[30] F.W. Yu, K.T. Chan, Modelling of the coefficient of performance of an air-cooled screw chiller with variable speed condenser fans, Build. Environ. 41 (2006) 407-17. doi:10.1016/j.buildenv.2005.02.002.

[31] V. Vakiloroaya, M. Khatibi, Q.P. Ha, B. Samali, New Integrated Hybrid Evaporative Cooling System for HVAC Energy Efficiency Improvement, in: System Integration (SII), 2011 IEEE/SICE International Symposium, 2011: pp. 772-8. doi:10.1109/SII.2011.6147546.

[32] D. Monfet, R. Zmeureanu, Ongoing commissioning of water-cooled electric chillers using benchmarking models, Appl. Energy. $92 \quad$ (2012) 99-108. doi:10.1016/j.apenergy.2011.10.019.

[33] Y. Yao, Z. Lian, Z. Hou, X. Zhou, Optimal operation of a large cooling system based on an empirical model, Appl. Therm. Eng. $24 \quad$ (2004) 2303-21. doi:10.1016/j.applthermaleng.2004.03.006.

[34] T.S. Lee, W.C. Lu, An evaluation of empirically-based models for predicting energy performance of vapor-compression water chillers, Appl. Energy. 87 (2010) 3486-93. doi:10.1016/j.apenergy.2010.05.005.

[35] Testo 6682 Instruction manual, (n.d.). https://www.testo.org/resources/media/global_media/produkte/testo_6682/Testo_6682_Ex 
_-_Manual.pdf (accessed July 9, 2014).

[36] Krohne UFM 3030 Techinical Datasheet, (n.d.). http://cdn.krohne.com/dlc/TD_UFM3030_en_060424.pdf (accessed September 7, 2014).

[37] WIKA cable thermocouple Model TC40 Data sheet, (n.d.). http://www.wika.co.za/upload/DS_TE6540_en_co_2045.pdf (accessed July 17, 2014).

[38] W.F. Stoecker, J.W. Jones, Refrigeration And Air Conditioning, 2nd ed., McGraw-Hill, New York, 1982.

[39] W. Bornman, J. Dirker, D.C. Arndt, J.P. Meyer, Operational energy minimisation for forced draft, direct-contact bulk air cooling tower through a combination of forward and first-principle modelling, coupled with an optimisation platform, Energy. 114 (2016) 9951006. doi:10.1016/j.energy.2016.08.069.

[40] ASHRAE HANDBOOK FUNDAMENTALS, Atlanta, 2013.

[41] D. Arndt, Integrated dynamic simulation of large thermal systems, PhD Thesis, University of Pretoria, Pretoria, South Africa., 2000.

[42] G.Y. Jin, W.J. Cai, L. Lu, E.L. Lee, A. Chiang, A simplified modeling of mechanical cooling tower for control and optimization of HVAC systems, Energy Convers. Manag. 48 (2007) 355-65. doi:10.1016/j.enconman.2006.07.010.

[43] X. Wei, G. Xu, A. Kusiak, Modeling and optimization of a chiller plant, Energy. 73 (2014) 898-907. doi:10.1016/j.energy.2014.06.102. 